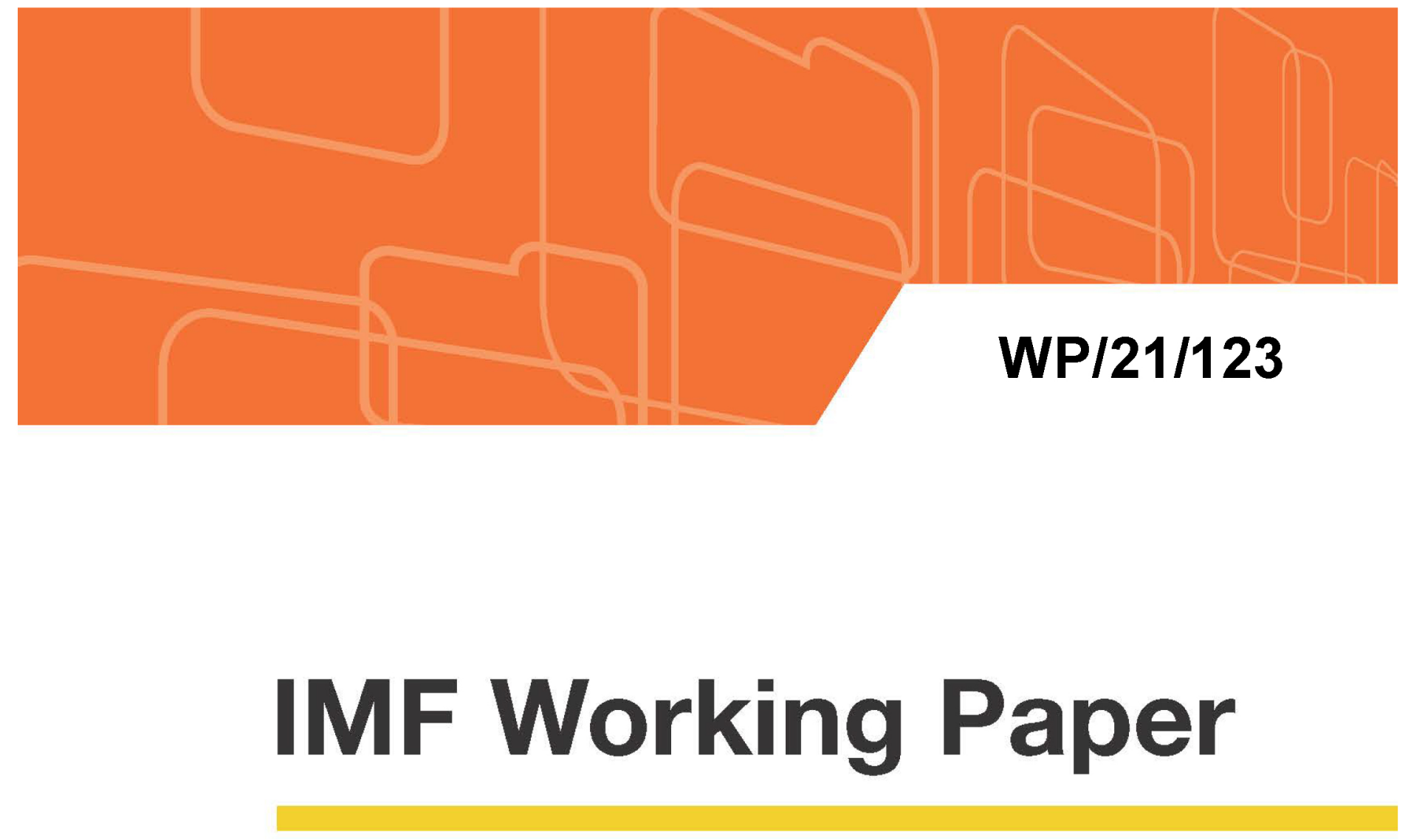

\title{
What Determines Social Distancing? Evidence from Advanced and Emerging Market Economies
}

by Era Dabla-Norris, Hibah Khan and Frederico Lima

IMF Working Papers describe research in progress by the author(s) and are published to elicit comments and to encourage debate. The views expressed in IMF Working Papers are those of the author(s) and do not necessarily represent the views of the IMF, its Executive Board, or IMF management.

I N T E R N A T I O N A L M O N E T A R Y F U N D 


\title{
IMF Working Paper
}

Asia \& Pacific Department

\section{What Determines Social Distancing? Evidence from Advanced and Emerging Market Economies}

\author{
Prepared by Era Dabla-Norris, Hibah Khan and Frederico Lima * \\ Authorized for distribution by Era Dabla-Norris
}

April 2021

\begin{abstract}
IMF Working Papers describe research in progress by the author(s) and are published to elicit comments and to encourage debate. The views expressed in IMF Working Papers are those of the author(s) and do not necessarily represent the views of the IMF, its Executive Board, or IMF management.
\end{abstract}

\begin{abstract}
The health and economic consequences of COVID-19 are closely tied to individual compliance with recommended protective behaviors. We examine the determinants of this compliance using survey data from the COVID Behavior Tracker for 29 advanced and emerging market economies between March and December 2020. Social distancing behaviors vary significantly by age, gender, occupation, and individual beliefs about COVID-19. In addition, those who trust their government's response to COVID-19 are significantly more likely to adopt recommended behaviors and to self-isolate if advised, highlighting the need for well-coordinated actions on the health and economic fronts. We also find that mobility restrictions, such as stay-at-home orders, and mask mandates are associated with reduced social interactions and persistent increases in compliance. Together, these drivers account for over two-thirds of the regional differences in compliance, confirming their important role in increasing social distancing and containing the pandemic.
\end{abstract}

JEL Classification Numbers: D91, H12, I18

Keywords: social distancing; COVID-19; trust in government

Author's E-Mail Address: edablanorris@imf.org; flima@imf.org; HKhan2@imf.org

\footnotetext{
* We would like to thank Sarah Jones at Imperial College, London, for sharing earlier versions of the dataset and seminar participants at the IMF for the useful comments.
} 


\section{CONTENTS}

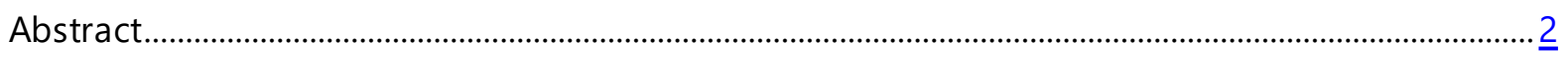

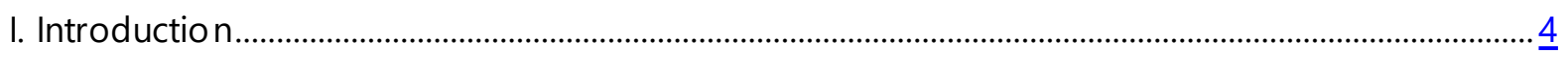

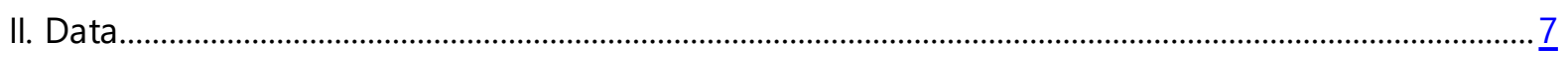

III. Social Distancing Since The Start of the Pandemic ……................................................................... $\underline{9}$

IV. Individual Determinants of Social Distancing................................................................................... 12

Empirical specification .................................................................... Error! Bookmark not defined.

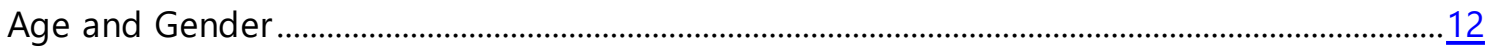

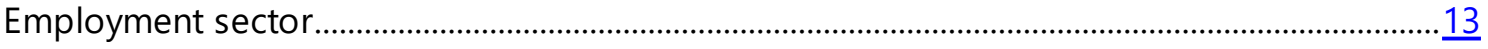

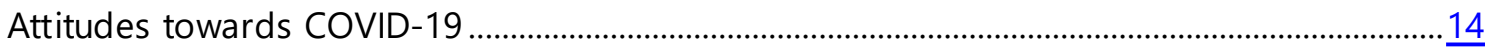

Confidence in the government's COVID-19 response...................................................................

V. Lockdowns, Mask Mandates, and Social Distancing........................................................................... 17

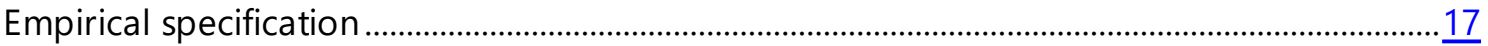

How lockdowns impact physical distancing...................................................................................

How mask mandates impact mask wearing....................................................................................... 19

VI. What Drives Country Differences in Compliance? .................................................................................. 22

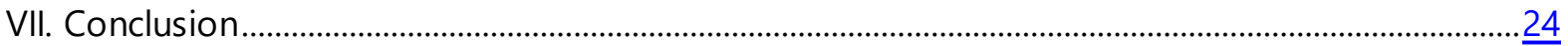

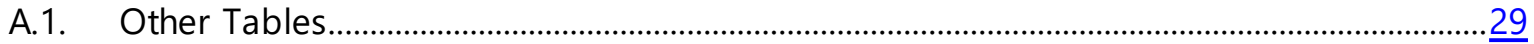

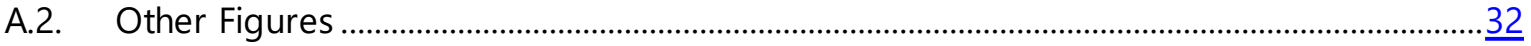




\section{INTRODUCTION}

Understanding the determinants of social distancing is central to addressing both the health and economic aspects of COVID-19. Compliance with stay-at-home orders, mask mandates, and other protective behaviors that limit the spread of illness can vary significantly across individuals, even within the same country. This can reflect differences in actual or perceived risk, the cost of social distancing behaviors, social norms, and even attitudes towards public health recommendations. Individual compliance with health directives can also depend on the degree of confidence or trust in the authorities. In the presence of strong externalities, individual behavior may not align with socially optimal outcomes, impacting the path of economic recovery.

We use individual-level data from the COVID-19 Behavior Tracker, a set of nationallyrepresentative surveys developed by YouGov and Imperial College London across 29 advanced and emerging market economies, to study the determinants of compliance with social distancing between March and December 2020. In addition to detailed information on respondents' characteristics and beliefs, the surveys cover a wide range of self-reported protective behaviors. This allows us to distinguish between different types of social distancing behaviors, including physical distancing and mask wearing, providing a comprehensive picture of individual differences in compliance in response to COVID-19 risks.

Our focus is on the factors that drive compliance with protective behaviors, and not whether those behaviors are effective at lowering health risks. First, we investigate how self-reported compliance has evolved across countries since the onset of the pandemic. Second, we examine how social distancing varies across demographic groups, occupations, risk attitudes, and confidence in the government response to COVID-19. Third, we examine how people respond to public health directives, particularly government-imposed lockdowns and mask mandates. Finally, we examine the role individual factors and government policies play in explaining differences in compliance across countries and regions.

As COVID-19 outbreaks began to ebb and lockdowns eased over the summer of 2020, widely used mobility indicators suggested that social distancing had begun to relax in many countries. ${ }^{1}$ We document that this was matched by a 20 percentage points decline in self-reported compliance with physical distancing between April and September 2020. This reflected a rapid increase in close contacts (i.e., within 6 feet) with non-household members, especially in countries that experienced stricter lockdowns earlier in the pandemic. However, the decline in physical distancing was also accompanied by a rapid adoption of mask wearing in public, particularly in countries that implemented mask mandates earlier on.

Turning to the role of individual determinants, we find systematic differences in compliance across demographic groups. For example, compliance with physical distancing increases sharply with age, with older people, who face a higher infection risks, reporting much higher compliance

\footnotetext{
${ }^{1}$ These aggregate mobility indicators are provided by several private companies, like Google, Apple, SafeGraph or Baidu (e.g., Chetty et al., 2020; WEO, 2020; Maloney and Taskin, 2020).
} 
than younger cohorts across a range of behaviors. Women also consistently report stronger adherence to social distancing compared to men. This gender difference is observed across different behaviors, tends to increase with age, and is robust to controlling for employment status and household composition. Together, this suggests that the gender gap in compliance is not driven by differences in labor market attachment, domestic work, or childcare responsibilities, and may (partly) reflect gender differences in risk preferences (e.g., Croson and Gneezy, 2009; Dabla-Norris et al., 2021).

There are also large differences in compliance across sectors. Naturally, compliance with physical distancing is significantly higher among those who can telework, even after controlling for outbreak dynamics and lockdown policies. However, there is also considerable variation in compliance among essential workers. For example, compliance with physical distancing behaviors and mask wearing is higher in female-dominated sectors-such as retail and hospitality-compared to more male-dominated sectors-like security, construction, or logistics. This suggests that sectoral heterogeneity in compliance to some extent reflects differences in gender and social norms across occupations.

Beliefs and attitudes towards COVID-19 are another major driver of compliance. First, respondents who are more fearful of contracting infections are also more likely to adopt protective behaviors: they are 20 percentage points more likely to avoid people exposed to COVID-19 and 8 percentage points more likely to wear face masks. Second, beliefs about the effectiveness of containment measures and confidence in the government's response to the pandemic are also associated with greater adherence to social distancing. This trust compliance gap is positive, large and statistically significant for a wide range of behaviors: respondents with more confidence in their government's response are 7 percentage points more likely to avoid contact with other people exposed to COVID-19, report 5 percent fewer close contacts with people outside their household, and are 14 percentage points more likely to isolate if advised by a healthcare professional.

In the second part of the paper, we use an event-study approach to estimate the impact of mobility restrictions on compliance, focusing on stay-at-home orders and mask mandates. We find that mobility restrictions are associated with large and persistent increases in physical distancing. For example, stay-at-home orders are associated with a persistent and significant increase in physical distancing of just over 5 percentage points. We find similar impacts on compliance in response to domestic mobility restrictions or workplace closures, indicating that much of the increase in physical distancing due to lockdowns is connected to workplace closures, and thus possibly caused by fewer work-related social interactions. We also do not observe any significant anticipation effects before these restrictions are announced, which supports the idea that we are capturing the causal impact of lockdown policies on physical distancing.

Similarly, we find that mask mandates are associated with a significant increase in mask wearing, with self-reported usage on average increasing by about 30 percentage points above the premandate baseline. These effects appear to be persistent, with mask wearing compliance 
remaining elevated over the ensuing months. People who believe that masks will protect them (or others) from contracting the disease respond more strongly to mask mandates than people with the opposite beliefs. We also find that differences in compliance due to varying trust in government can be overcome through mask mandates, with similar impacts of mandates across people with high and low trust. Our results support the idea that, before vaccines and treatments become widely available, low-cost non-pharmaceutical interventions such as mask mandates can play an important role in slowing the spread of the COVID-19 pandemic.

In the last section, we bring our analysis together to understand how much of the regional differences in compliance can be attributed to individual factors and government interventions. Following the conditional decomposition proposed by Gelbach (2016), we show that individual characteristics and beliefs and government policies explain over two-thirds of that variation. This confirms the important role of public health policy in shaping compliance, but also points to the role of other potential compliance drivers-e.g., COVID-19 risk, social norms, enforcement, and communication (see, for example, IMF, 2020; Maloney and Taskin, 2020).

Our paper is part of a growing literature examining the determinants of compliance with social distancing recommendations. Recent studies have found significant gender and age differences in compliance, with women and older individuals being more likely to perceive the pandemic as a serious health problem and to report compliance with social distancing measures (Galasso et al., 2020; Belot et al., 2020). ${ }^{2}$ Others have examined links between social distancing and income (e.g., Chiou and Tucker, 2020), work flexibility (Papageorge et al., 2020), political beliefs (Allcott et al., 2020; Barrios and Hochberg, 2020), risk preferences (Fan et al., 2020) and media choices (Simonov et al., 2020). ${ }^{3}$ Much of this research focuses on advanced economies at the start of the pandemic. We contribute by analyzing a richer survey dataset covering 29 countries, including several emerging markets, and examining how compliance has changed over time.

An extensive literature before the pandemic also finds that higher trust in public institutions is associated with adherence to public health interventions (e.g., Salmon et al., 2015; Mohseni and Lindstrom, 2007). Trust also appears to matter significantly in the case of COVID-19. For example, Han et al. (2020) find that trust is associated with increased adoption of social distancing behaviors across multiple countries, while Bargain and Aminjonov (2020) find higher compliance among European regions with higher levels of trust in government. ${ }^{4}$ We also find that confidence

\footnotetext{
${ }^{2}$ Similar gender and age differences in social distancing compliance have been found for country-specific studies, including the U.S. (Li et al., 2020) and Austria (Reisch et al., 2020). Caselli et al. (2021) show that lockdowns had a larger impact on the mobility of women and younger individuals, using data for Italy, Spain, and Portugal. Haischer et al. (2020) find that older individuals and females were much more likely to wear masks in US retail stores before stores adopted mask requirements. Additionally, the odds of observing a mask on an urban or suburban shopper were about four times that for rural areas.

${ }^{3}$ Brodeur et al. (2020) offers a survey of the literature on the economic impact of COVID-19 and related government responses.

${ }^{4}$ Durante et al. (2020) and Barrios et al. (2021) highlight the role of social norms in driving compliance. Ajzenman et al. (2020) show that compliance with social distancing measures declined in pro-government localities in Brazil after the president dismissed the risks of the COVID-19 pandemic and advised against isolation, especially in more Facebook connected municipalities.
} 
in the government response to COVID-19 determines compliance, especially for contingent behaviors such as isolating when recommended by a healthcare professional.

Finally, our paper also contributes to research on the effects of public health interventions, including lockdowns, on compliance. One strand of this literature examines the impact of lockdowns on mobility indicators based on geolocation data (e.g., IMF, 2020; Maloney and Taskin, 2020). Although these indicators have been used extensively, we show that they are an incomplete proxy for social distancing, and their elasticity to self-reported physical distancing behaviors appears to be declining over time. We also contribute by examining how beliefs about COVID-19 and the government response impact compliance, important dimensions that are not captured by mobility data.

Mask mandates have also been found to increase compliance with mask wearing in different contexts. For example, Haischer et al. (2020) find that mask mandates in US retail stores increased compliance by about 90 percent of shoppers. Karaivanov et al. (2020) find that mask mandates in Canada increased reported mask usage by about 30 percent. We show that the positive impacts of mandates on mask wearing are observed across a large sample of countries, and their effects appear to be persistent. However, we also find that the increase in mask wearing in many countries was matched by less physical distancing, suggesting that people trade-off the risks and costs of different social distancing behaviors (Yan et al, 2021).

The remainder of the paper is organized as follows. Section II presents the data, and Section III discusses how COVID-19-related social distancing has changed over time. Section IV examines the individual determinants of social distancing in more detail, while Section V illustrates the impact of public health messaging on compliance, focusing on lockdowns and mask mandates. Section VI examines the combined role of these factors in explaining compliance differences across countries. The last section concludes.

\section{DATA}

We use publicly-available data from the COVID-19 behavior tracker, a survey developed by YouGov and the Institute of Global Health Innovation (IGHI) at Imperial College London to gather global insights on people's behaviors in response to COVID-19. The dataset contains individuallevel responses from nationally-representative surveys carried out in 29 advanced and emerging market economies, covering questions on COVID-19 symptoms, testing, attitudes, and compliance with social distancing recommendations. ${ }^{5}$

Our dataset includes all surveys conducted between March and December 2020, spanning over 420,000 individual observations. The surveys aim to be broadly representative of the general

\footnotetext{
${ }^{5}$ Our sample covers Australia, Brazil, Canada, China, Denmark, Finland, France, Germany, Hong Kong SAR, India, Indonesia, Italy, Japan, Malaysia, Mexico, Netherlands, Norway, Philippines, Saudi Arabia, Singapore, South Korea, Spain, Sweden, Taiwan, province of China, Thailand, United Arab Emirates, United Kingdom, United States, and Vietnam. The data can be downloaded from https://github.com/YouGov-Data/covid-19-tracker/
} 
public in each country, and typically have around 1,000 respondents in each round. ${ }^{6}$ Surveys were conducted bi-weekly in most countries, except in the United Kingdom and a few other advanced economies early on in the pandemic, which were surveyed weekly. The coverage of the surveys narrowed after October 2020 to cover only 15 countries out of the original 29. Details on data availability by country and over time are presented in Figure A. 1 in the appendix.

The surveys cover a wide range of recommended social distancing behaviors, including how often respondents go outdoors, work from home, use masks or avoid touching objects in public spaces, wash hands, send their children to attend school in person, host guests at home, attend small, medium or large social gatherings, and purposefully avoid crowds. Individual responses are self-reported, and mostly coded qualitatively-for example, whether the respondent follows the recommended behavior "Always", "Frequently", "Sometimes", "Rarely" or "Not at All."

Given the large number of behaviors tracked in the survey, we focus on a set of behaviors recommended by the US Center for Disease Control to prevent transmission of COVID-19. ${ }^{7}$ We construct a physical distancing compliance index that takes value one if individuals report that they "Always" or "Frequently" comply simultaneously with all of the following behaviors: (i) avoiding close contact with other people, including staying at least 6 feet away from people not living in the same household, (ii) frequent handwashing, (iii) covering coughs and sneezes, and (iv) cleaning frequently touched surfaces daily. We proxy the avoidance of non-household close contacts with responses to questions on avoiding contact with people who have symptoms or may have been exposed to COVID-19 and avoiding social gatherings to protect themselves or others from contracting COVID-19. The CDC also recommends covering mouth and nose with a face mask when around others, and we examine compliance with this recommendation separately.

In addition, our dataset includes rich contextual information, such as gender, age, health and employment status, household size, and the number of children in the household, as well as a weighting variable based on age, gender and region, which we use throughout our analysis. Regarding occupation, the data includes information on whether respondents work outside their home, and for those that do, the economic sector they work in. We also use measures of individual attitudes towards COVID-19, as well as confidence in their government's handling of the COVID-19 crisis and the ability of national health systems to respond to the crisis. These latter questions are however not available in selected economies in our sample, namely China, Hong Kong SAR, Thailand, Saudi Arabia, and the United Arab Emirates. Finally, we take data on confirmed COVID-19 cases and deaths from the COVID-19 Data Repository by the Center for Systems Science and Engineering (CSSE) at Johns Hopkins University (Dong et al., 2020), and information on the stringency of government lockdowns and adoption dates of government

\footnotetext{
${ }^{6}$ In China and India, the surveys are only representative of the online and urban online populations, respectively.

${ }^{7}$ See https://www.cdc.gov/coronavirus/2019-ncov/prevent-getting-sick/prevention.html
} 
policies related to COVID-19 from the Oxford Covid-19 Government Response Tracker (Hale et al., 2020).

\section{Social Distancing Since The Start OF the Pandemic}

We start our analysis by plotting the share of survey respondents that "Always" or "Frequently" comply with social distancing recommendations, separating between physical distancing behaviors and mask wearing. To abstract from changes in country coverage over time, we focus on a balanced sample of 15 countries that were surveyed consistently throughout the sample period. However, the results are similar if we consider all countries in our sample.

Both panels in Figure 1 suggest that there has been a significant decline in social distancing since the start of the pandemic. The panel on the left shows that the share of people complying with all physical distancing recommendations declined by 20 percentage points between April and September 2020. The share of compliers ticked up again in the last quarter of 2020, coinciding with colder weather in the Northern Hemisphere and the reintroduction of mobility restrictions and partial government lockdowns in several countries. Still, the share of compliers remained at least 10 percentage points below the April peak.

Figure 1. Declining social distancing
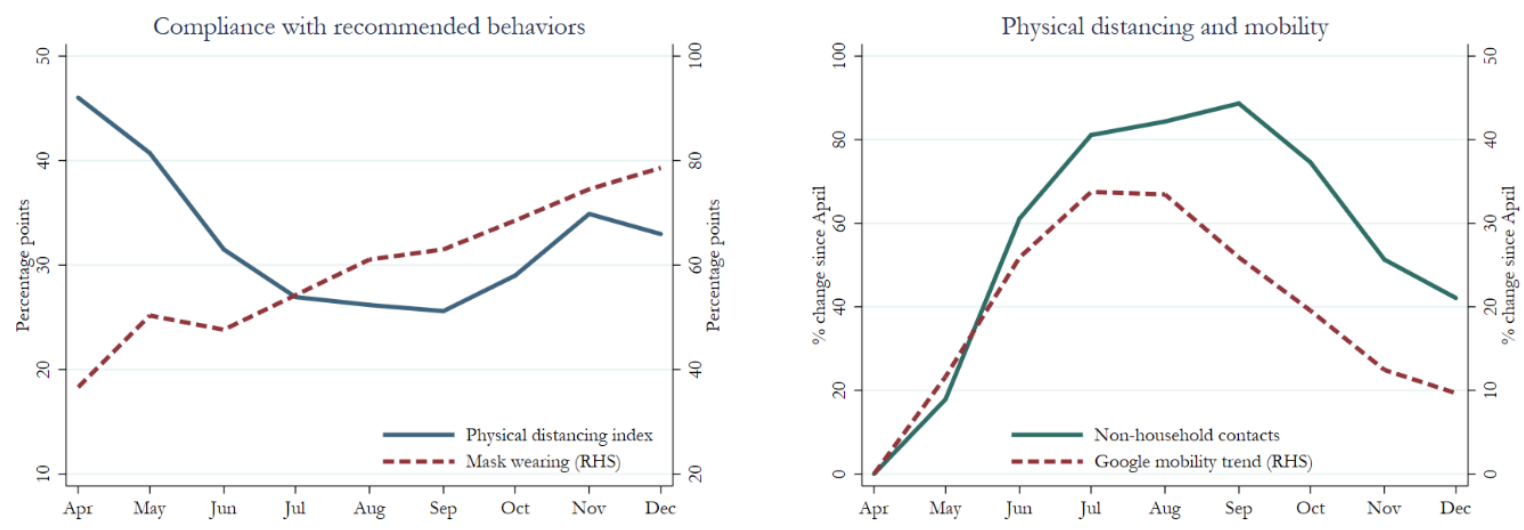

Note: The left panel shows the share of respondents that comply with mask wearing and recommended physical distancing behaviors-frequent handwashing, covering coughs and sneezes, cleaning frequently touched surfaces, avoiding people exposed to COVID-19 and avoiding small social gatherings. The right panel shows the average percent change in contacts with people outside the respondents' household and the Google mobility trends indicator, relative to a country-specific April baseline. The analysis is restricted to 15 countries that were surveyed every month since April 2020. A similar analysis for the full sample is shown in Figure A.2 in the appendix.

The panel on the right shows that the decline in social distancing was particularly pronounced for close contacts with non-household members, defined as spending time in close physical proximity (i.e., within 2 meters or 6 feet of distance). On average, close contacts increased steadily after April, and were up by almost 90 percent as of September, before declining significantly from October onwards. This trend in close non-household contacts mirrors the evolution of the physical distancing index in the left panel and is also strongly correlated with mobility indicators widely used in the literature, such as Google mobility trends (e.g., IMF 2020). These indicators show a similar hump-shape pattern, although the decline in mobility both 
precedes and exceeds the reported decline in close contacts. This suggests that mobility indicators were a good proxy for physical distancing, especially early on in the pandemic, but the elasticity of self-reported compliance to mobility appears to be declining over time.

Despite this decline in physical distancing, people did not abandon social distancing altogether. First, the share of people that reported non-compliance with all recommend behaviors remained low and steady over the same period, hovering around 3 percent of all respondents. Second, and more importantly, the left panel in Figure 1 shows that lower physical distancing was matched by a large increase in mask wearing outside the home, especially in countries where mask wearing was not common before the pandemic. This suggests that many respondents sought to mitigate the risk of increased physical proximity by wearing masks (see also Yan et al., 2021). It also shows that social distancing has multiple dimensions, some of which are not accurately captured by mobility indicators.

Country-specific trends portray a similar picture. Figure 2 looks at changes in compliance over time for each of the 29 countries in our sample. Specifically, we separate survey responses in the first half of 2020 - a period that covers the initial COVID-19 outbreaks and stricter government lockdowns-from those in the second half of 2020-when many countries in our sample experienced a second wave of COVID-19 infections and a reintroduction of mobility restrictions. The top panel examines the evolution of physical distancing, while the bottom panel looks at compliance with mask wearing.

Across almost all countries, we observe a significant decline in physical distancing, but increased adherence to mask wearing. For physical distancing, the decline in compliance appears to be larger in countries that experienced stricter lockdowns earlier in the pandemic, such as Italy, Spain, Singapore and the United Kingdom. Similarly, self-reported mask wearing appears to have risen almost everywhere, but the increase was especially large in countries that adopted mask mandates earlier. This includes early mask mandate adopters-where there was a large increase in mask wearing in January and February, before the start of our sample period-as well as countries like Canada, France, Germany and the United Kingdom, where mask mandates were implemented a few months after. For the latter, Figure 2 shows a large increase in mask wearing between the first and second halves of 2020. By contrast, countries that adopted mask recommendations or mandates later in the year-like many countries in Northern Europe-saw a smaller and more gradual increase in mask wearing compliance. These differences suggest an important role for government policies, such as mask mandates and mobility restrictions, in driving changes in social distancing over time, and also in explaining cross-country differences in compliance.

In the next two sections, we explore the determinants of these trends in social distancing since the start of the pandemic. We first focus on how compliance varies with individual factors, including personal beliefs and attitudes towards COVID-19, and then examine how compliance responds to government policies such as mobility restrictions and mask mandates in section $\mathrm{V}$. 
Figure 2. Compliance with social distancing by country
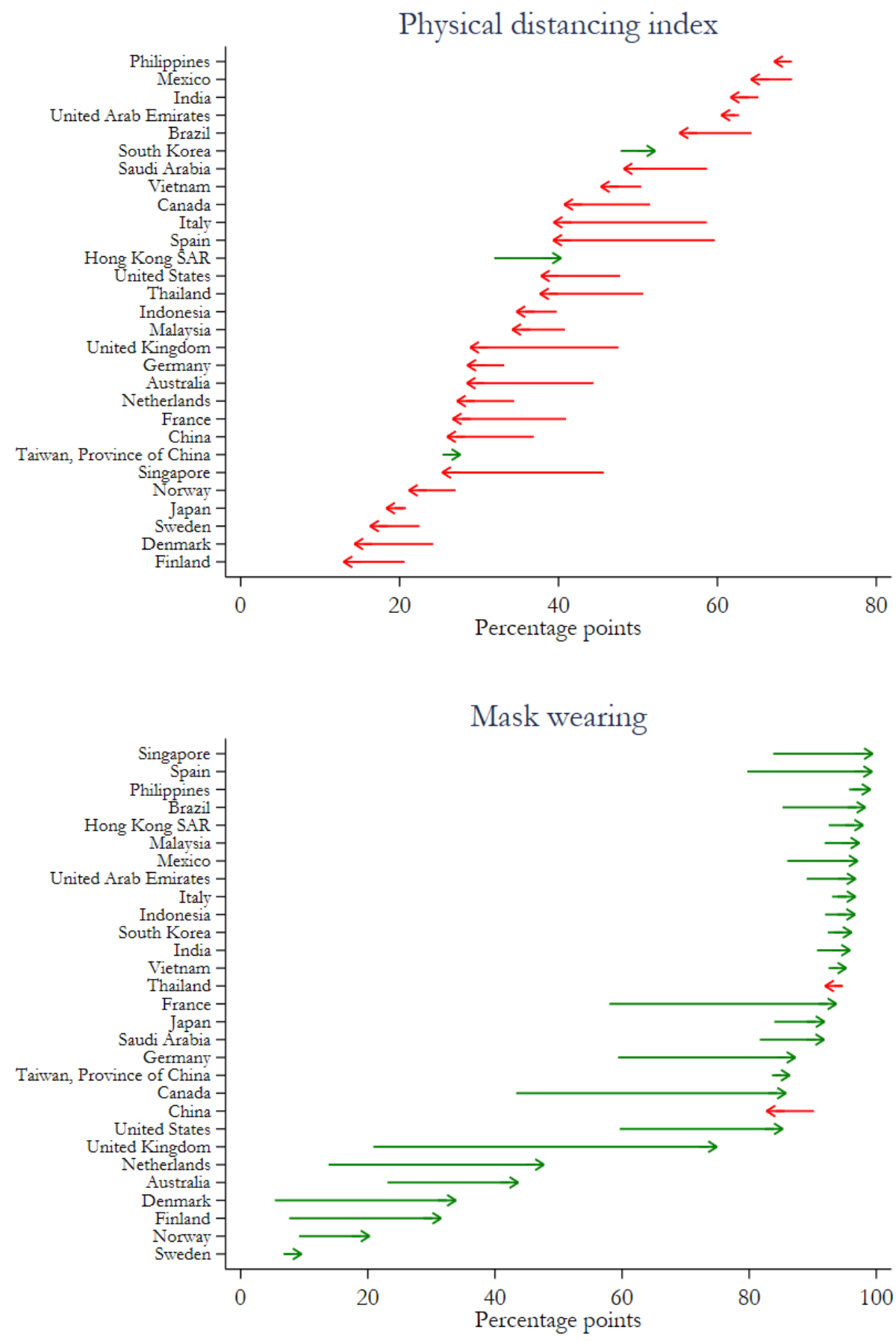

Note: The panels show the percentage of respondents complying with recommended social distancing behaviors, separating between physical distancing and mask wearing. For each country, the start of each arrow indicates the average share of respondents complying during the period March to June, while the arrow shows average compliance in the second half of 2020. Green (red) arrows indicate an increase (decrease) in compliance over time. 


\section{INDIVIDUAL DETERMINANTS OF SOCIAL DISTANCING}

\section{Empirical specification}

In this section, we examine how compliance differs across socioeconomic groups and how it is impacted by individual beliefs and attitudes towards COVID-19, and confidence in the government's response. Our analysis starts from the following linear probability model specification:

$$
\text { Compliance }_{i c t}=\mu_{c t}+\beta^{\prime} \text { Group }_{i c t}+\gamma^{\prime} Z_{i c t}+e_{i c t}
$$

where Compliance takes value 1 if individuals report that they "Always" or "Frequently" comply with the recommended social distancing behaviors, and 0 otherwise, and Group is a vector of group identifiers, such as gender or age cohort. We focus on two measures of compliance, the physical distancing index described above and mask wearing outside the household.

To abstract from time and country variation in COVID-19 dynamics and policy interventions (e.g., stringency of government lockdowns), and to control for differences in survey design across countries and over time, all regressions condition on country-specific, survey wave fixed effects $\mu$. We also include a set of demographic controls, such as household size, number of children, employment status and occupation, as well as controls for respondent health status, including whether the respondent or someone in their household tested positive for COVID-19, are currently experiencing COVID-19-like symptoms, or belong to a high-risk group for COVID-19 due to underlying health conditions.

\section{Age and Gender}

We first examine how compliance with social distancing varies with age and gender. Age is an important driver of compliance, since COVID-19 mortality and morbidity appears to increase exponentially with age (Levin et al., 2020; O'Driscoll et al., 2020). We would therefore expect compliance with social distancing to increase with age, especially among older people. Gender is another potential driver of compliance, as men have been shown to be at higher risk for severe COVID-19 outcomes compared to women (Peckham et al., 2020). This suggests that men would have a stronger incentive to comply with social distancing, or that differences in behaviors among men increases their risk from COVID-19.

Using the specification described in Equation (1), we estimate the average age profiles in social distancing compliance among men and women, across all countries in our sample. The estimated coefficients are plotted in Figure 3 and are shown as percentage point increases (or declines) relative to the 18 to 24 year-old male cohort. The impact for this baseline cohort is zero by construction.

Compliance with physical distancing increases sharply with age, especially among women. Older cohorts report much higher rates of physical distancing, with an increase of 11 percentage points 
(for men) and 18 percentage points (for women) compared to younger cohorts. The age profile in mask wearing is flatter and non-monotonic, with typically higher compliance among younger and older cohorts compared to middle-age cohorts.

Figure 3. Compliance by age and gender
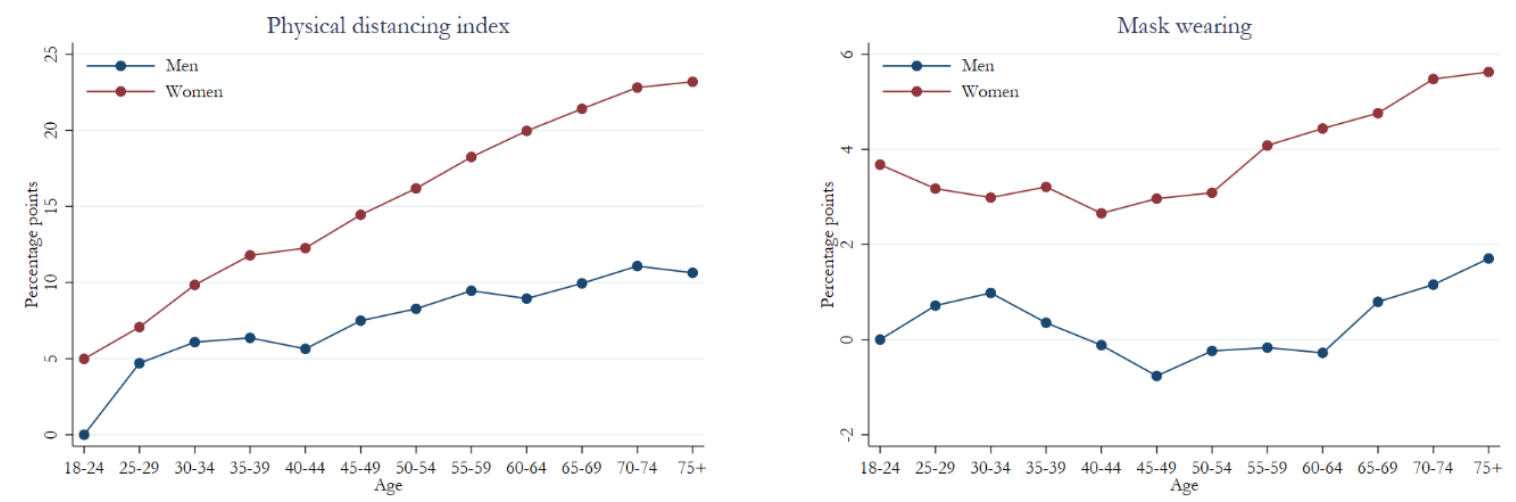

Note: The panels show the average difference in compliance by age and gender, relative to the cohort of 18 to 24 year old males. The coefficients are estimated using Equation (1), and displayed in percentage points. Both specifications include survey fixed effects, and control for household size, number of children, employment status and occupation, and respondent health status. More details are presented in Table A.2 in the appendix.

Both panels of Figure 3 also show that compliance is consistently higher among women compared to men. While this gender difference is present and statistically significant across all cohorts, it tends to be larger among older cohorts, especially for compliance with physical distancing recommendations. The fact that men are on average less compliant with social distancing recommendation may be one explanation for why they seem to be at higher risk for severe COVID-19 outcomes compared to women.

These age and gender compliance gaps are unlikely to be driven by differences in labor market attachment or norms around domestic work and childcare responsibilities. First, our regression specification already controls for employment status and occupation type (including whether or not respondents work from home), household size and number of children. Second, the results are also essentially unchanged when we restrict our analysis to individuals in full-time employment, as shown in the appendix. Finally, the gender gap in compliance is observed even among the youngest and oldest age cohorts, for whom these factors are less important. These results are also not driven by how we construct the physical distancing index, as we observe similar patterns for different individual behaviors, as shown in the appendix.

\section{Employment sector}

Next, we examine differences in compliance across employment sectors. We start by restricting the analysis to full and part-time workers, separating between those working from home from those who are not able to telework. Among the latter, we also have information on the sector they work in. We continue to use the specification described in Equation (1), and control for age, gender, household composition, and health status. The estimated coefficients are plotted in 
Figure 4 as percentage point increases (or declines) relative to compliance among manufacturing workers as a baseline group.

Figure 4. Social distancing by employment sector
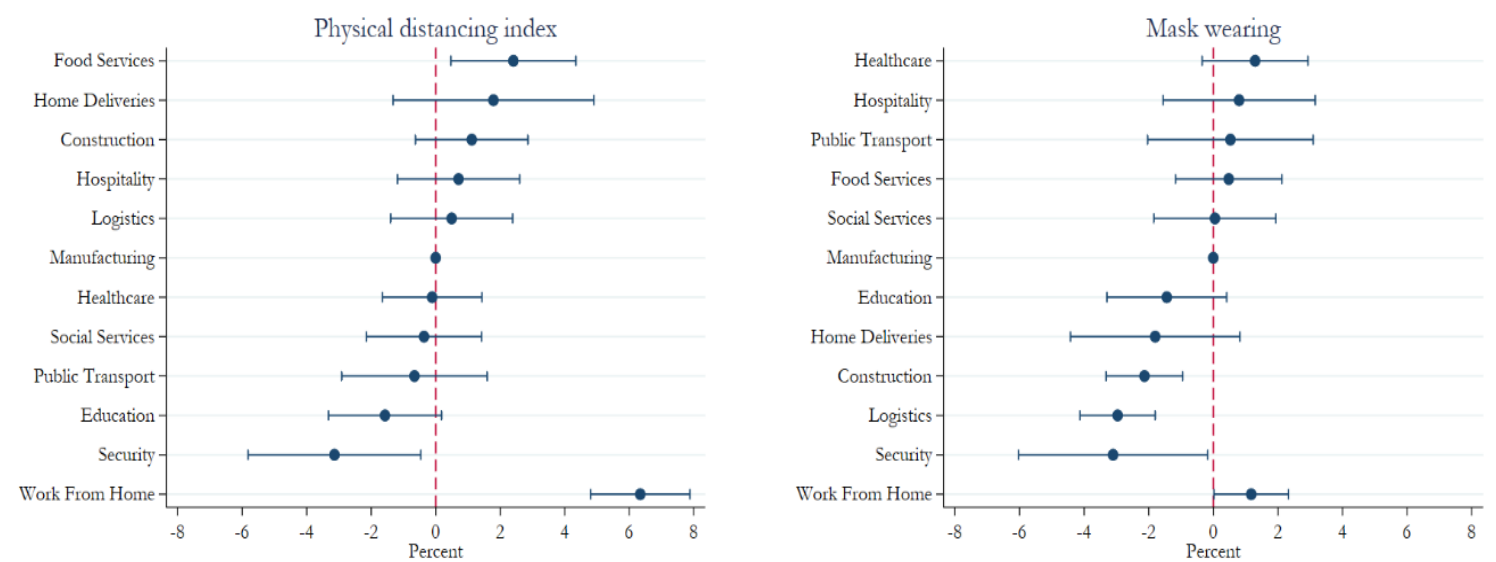

Note: These panels estimate average compliance differences by employment sector, in percentage points. The baseline group is workers in the manufacturing sector that are not able to telework, and the sample is restricted to full and part-time workers. The 95 percent confidence intervals are based on robust standard errors clustered on country. All regressions are based on Equation (1), include survey fixed effects, and control for age, gender household composition, and respondent health status. More details are presented in Table A.3 in the appendix.

There are large differences in compliance with physical distancing across sectors. Not surprisingly, compliance is much higher among teleworkers, with an average increase in compliance of over 6 percentage points relative to manufacturing workers. However, significant differences in compliance are also observed across different types of essential occupations. For example, compliance with physical distancing is higher among workers engaged in food services-a sector that tends to be female-dominated-compared to workers in the security and public transport—which are more male-dominated (e.g., Brussevich et al., 2019). This suggests that differences across sectors could be due to differences in gender and social norms within occupations, and not just the type of activities involved (e.g., more client-facing or group-based).

We also find sizable differences in compliance with mask wearing across sectors. Here, the compliance gap between those working from home and those in essential occupations is not as large. We also find that mask wearing is more prevalent in occupations such as healthcare, as well as in client-facing sectors such as hospitality and retail food services. Conversely, we find lower compliance rates in occupations such as security, construction and logistics, which tend to be male-dominated.

\section{Attitudes towards COVID-19}

Our dataset also includes several questions focused on personal attitudes towards COVID-19, which are an important determinant of social distancing. Among these, respondents described whether they were "Very", "Fairly", "Not Very" or "Not at All" scared of contracting COVID-19 sometime in the future (or if they already contracted COVID-19). Using the specification described before, we examine differences in compliance across a range of behaviors between 
people that reported being "Very Scared" and those who were "Not Scared at All". We continue to control for age, gender, household composition, and health status, and also control for employment sector and survey fixed effects.

Figure 5. Social distancing and attitudes towards COVID-19
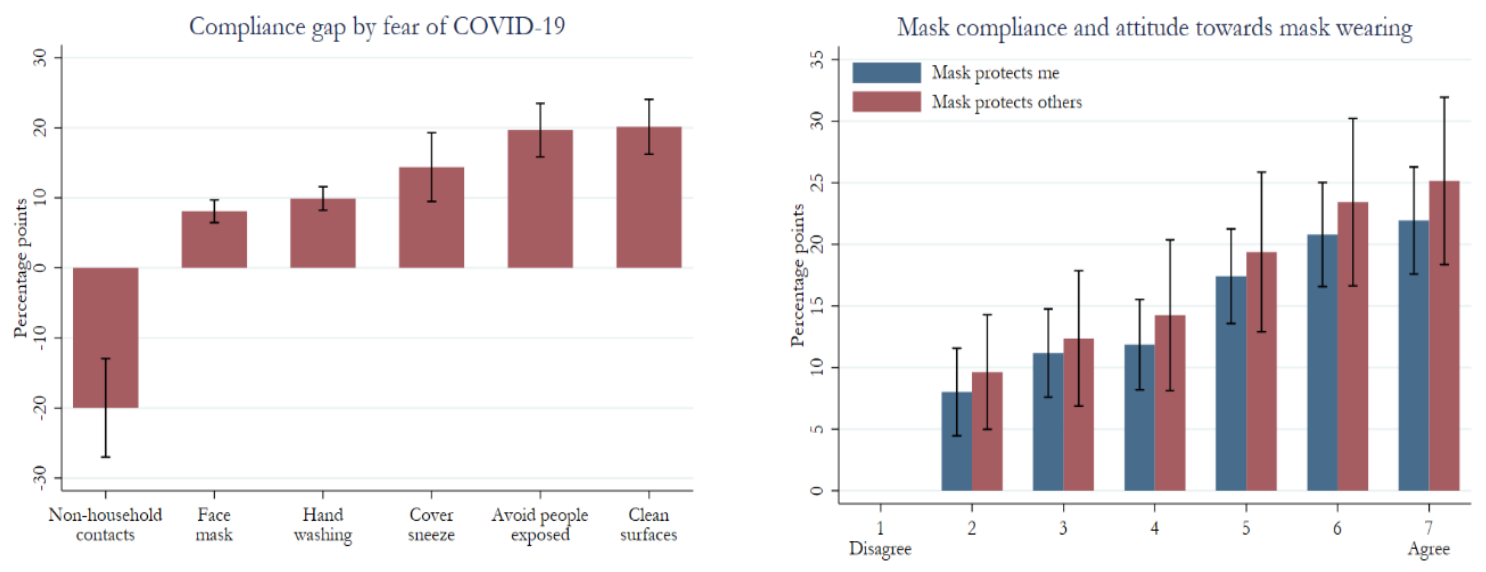

Note: The left panel shows the average compliance gap (in percentage points) between respondents that report feeling very scared of contracting COVID-19 and respondents not feeling scared at all. The right panel shows the difference in compliance with mask wearing, conditional on whether respondents agree that masks protect them or others. Both panels are based on Equation (1), conditional on survey fixed effects, and include controls for age, gender, household composition, employment, and health status. The 95 percent confidence intervals are based on robust standard errors clustered on country. More details about the fear compliance gap are shown in Figure A.5 in the appendix.

As shown in the left panel of Figure 5, actual or perceived risk of COVID-19 is a major driver of compliance. Respondents with more fear of contracting COVID-19 are much more likely to adopt all recommended behaviors, and these differences are all statistically significant. For example, they are 20 percentage points more likely to avoid people exposed to COVID-19, 10 percentage points more likely to wash hands frequently, and about 8 percentage points more likely to wear face masks. They also report having 20 percent fewer contacts with non-household members.

We also examine if individual beliefs about the effectiveness of social distancing impact compliance. In particular, survey respondents were asked if they agreed that masks would protect themselves and others against COVID-19, on a scale from 1 (Disagree) to 7 (Agree). The right panel of Figure 5 plots the estimated differences in compliance with mask wearing conditional on the answer to this question, taking 1 (Disagree) as the baseline. Compliance with mask wearing increases linearly with the perceived effectiveness of face masks, and the magnitude of this impact can be quite large-for example, mask wearing is 25 percentage points higher among those who believe that mask wearing is effective compared to those who do not. This suggests that influencing beliefs about the effectiveness of social distancing plays an important role in shaping compliance.

\section{Confidence in the government's COVID-19 response}

Finally, we examine how compliance with social distancing varies with respondents' confidence in their government's response to COVID-19. We continue to use the specification in Equation (1), 
and the same set of controls for age, gender, household composition, employment, and respondent health status.

Figure 6. Social distancing and trust in government
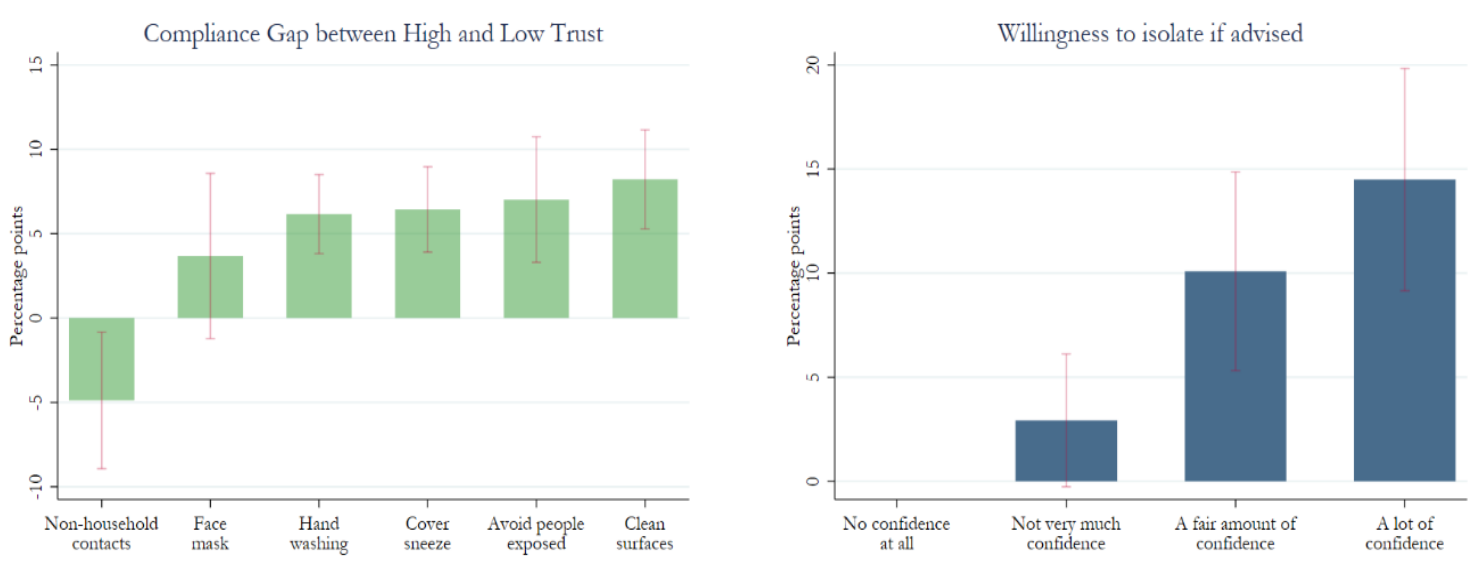

Note: The left panel shows the average compliance gap between respondents with a lot of confidence and no confidence at all in their government's response to COVID-19, in percentage points, across different behaviors. The right panel shows the average difference in respondents' willingness to isolate if advised by a healthcare professional, depending on their confidence in their government's response to COVID-19. Both panels are based on Equation (1), conditional on survey fixed effects, and include controls for age, gender, household composition, employment, and health status. The 95 percent confidence intervals are based on robust standard errors clustered on country. See Figure A. 6 in the appendix for more details.

We start by focusing on average differences in compliance between those who report a lot or some confidence in the government's response to COVID-19, compared to those that report very little confidence or none at all. As before, we continue to use country-wave fixed effects in our regression specification. Thus, our results are based only on cross-individual variation in selfreported trust relative to a country-wave specific average, which attenuates some concerns about omitted variable bias, including from potential differences in the quality of trust questions across countries.

The results are shown in the left panel of Figure 6. Compliance with social distancing is stronger among respondents that are more confident in their government's response to COVID-19. This trust compliance gap is positive for a wide range of behaviors, and these differences tend to be large and statistically significant. For example, respondents with more confidence in their government's response are 6 percentage points more likely to wash their hands often, 7 percentage points more likely to avoid contact with other people exposed to COVID-19, and report 5 percent fewer close contacts with people outside their household in the two weeks prior to the survey.

Confidence in the government's response is also important for contingent behaviors that individuals may take if they become exposed to COVID-19. For example, as shown in the right panel of Figure 6, respondents who report high confidence in their government's COVID-19 response are 14 percentage points more likely to isolate if advised by a healthcare professional. Even those with only a fair amount of confidence are 10 percentage points more likely to isolate. This suggests that compliance with social distancing improves gradually with the degree of 
confidence in the government's response, suggesting that even incremental gains in trust are associated with higher compliance.

\section{LOCKDOWNS, MASK MANDATES, AND SOCIAL DISTANGNG}

While demographics and attitudes towards COVID-19 and the government response help to explain differences in compliance across countries, the decline in physical distancing since the start of the pandemic appears to be strongly correlated with public health interventions. In this section, we examine the impact of these interventions on compliance, focusing on the impact of government-imposed lockdowns and mask mandates.

\section{Empirical specification}

We estimate the impact of public health interventions using the following event-study specification:

$$
\text { Compliance }_{i, c, t}=\alpha_{c}+\sum_{\tau=-5}^{10} \beta_{\tau} \text { Policy }_{c, t-\tau}+\gamma^{\prime} Z_{i, c, t}+e_{i, c, t}
$$

Here, Compliance continues to be a measure of compliance with social distancing recommendations, like the physical distancing index or self-reported mask wearing, and the variable Policy refers to the implementation of public health interventions such as government lockdowns or mask mandates. The coefficients of interest are the $\beta_{\tau}$, which capture the impact of those policies on compliance. We focus on the impacts starting from 5 weeks before to 10 weeks after the policies were implemented, and we obtain these dates from the Oxford Covid-19 Government Response Tracker (Hale et al., 2020). Our focus on the weeks before implementation allows us to establish how compliance was trending before policies were announced, and therefore parse whether a potential compliance increase after implementation is associated with that policy or not.

Similar to before, our baseline specification conditions on country fixed effects to capture timeinvariant differences in compliance across countries, and also controls for a range of individual covariates, including age, gender, household composition, employment, respondent health status, and the lagged 7-day average of new confirmed COVID-19 deaths.

\section{How lockdowns impact physical distancing}

We start by analyzing how lockdowns, and in particular stay-at-home orders, impact physical distancing. In cases where stay-at-home orders were preceded by a similar recommendation by the government, we consider the date of recommendation as the date of implementation, to capture possible anticipation effects.

As Figure 7 shows, stay-at-home orders are associated with a large and persistent increase in physical distancing. This starts from the first week of implementation (as indicated by the dashed line) and builds over the following two weeks. The impact is gradual, in part reflecting the fact 
many countries announced restrictions first on a voluntary basis, as a public health recommendation, which were followed a few weeks after by more stricter requirements. Over time, stay-at-home orders are associated with a persistent, and statistically significant increase in physical distancing of about 5 to 7 percentage points. We also do not observe any significant anticipation effects before stay-at-home orders were implemented, as the estimated coefficients in the weeks leading up to implementation are close to zero and not statistically significant. This supports the idea our specification is able to capture the causal impact of these policies on physical distancing.

Figure 7. Lockdowns and physical distancing

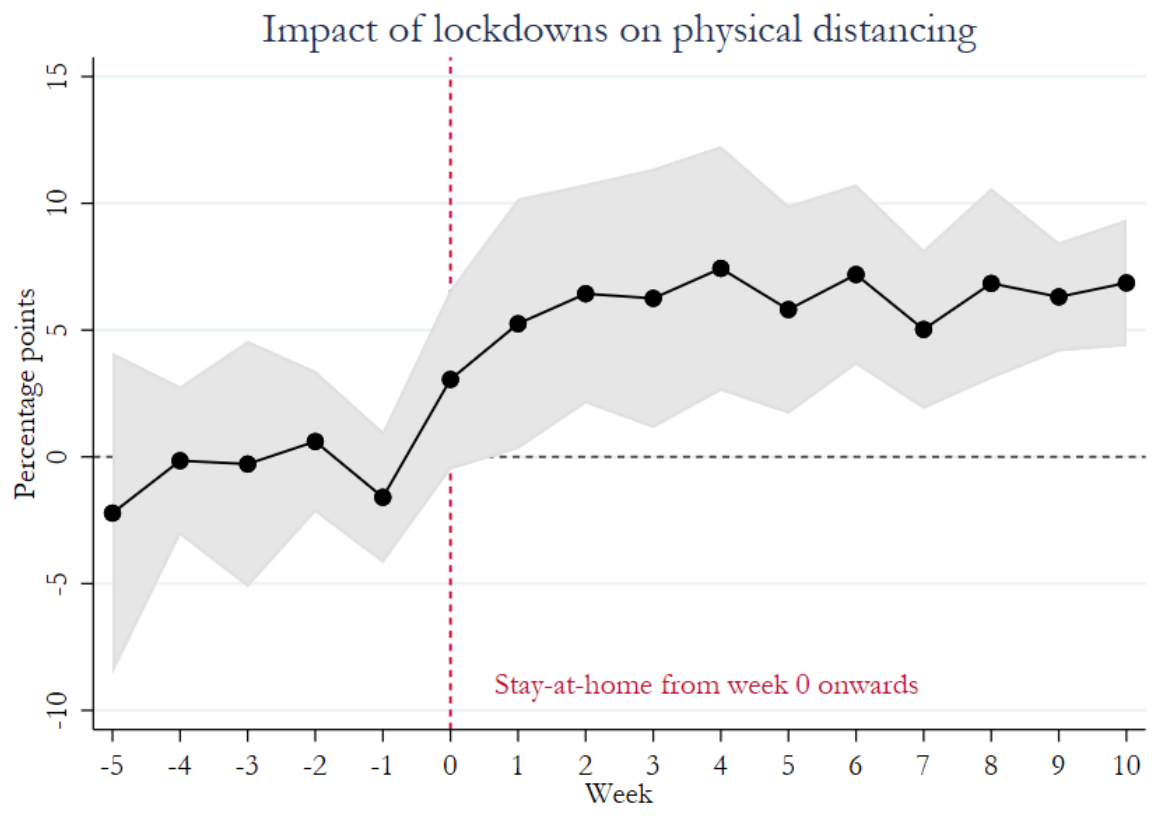

Note: This figure shows the impact of stay-at-home orders on the physical distancing index (in percentage points), before and after they came into effect. The dashed red vertical line indicates week 0 , when stay-at-home orders were implemented. The specification follows Equation (2), conditions on country fixed effects, and controls for age, gender, household composition, employment, respondent health status and new confirmed COVID-19 deaths. The panel also shows 95 percent confidence intervals based on robust standard errors clustered by country.

To understand what is driving this increase in physical distancing, we estimate the same specification, but this time focus on specific behaviors. In particular, we look at two indicator variables for individuals that have "Always" or "Frequently" avoided going out or avoided attending small social gatherings with non-household members (2 people or fewer) in the 7 days prior to responding to the surveys. The results are shown in the top row of Figure 8 . In both cases, stay-at-home orders are associated with a large and significant increase in the share of people that avoid socializing with non-household members, or avoid going out in general. The responses build gradually over the first weeks of the stay-at-home order, and appear to be persistent even two months after the policies were implemented. Overall, these results suggest that increases in physical distancing due to stay-at-home orders are related to lower individual mobility and reduced contacts with non-household members. 
In the bottom row of Figure 8 , we examine the impact of other restrictive policies that have been associated with government lockdowns in many countries-workplace closures and internal movement restrictions. The implementation dates for these policies are also taken from the Oxford Covid-19 Government Response Tracker (Hale et al., 2020).

Figure 8. Impact of lockdowns, robustness

(a) Specific behaviors
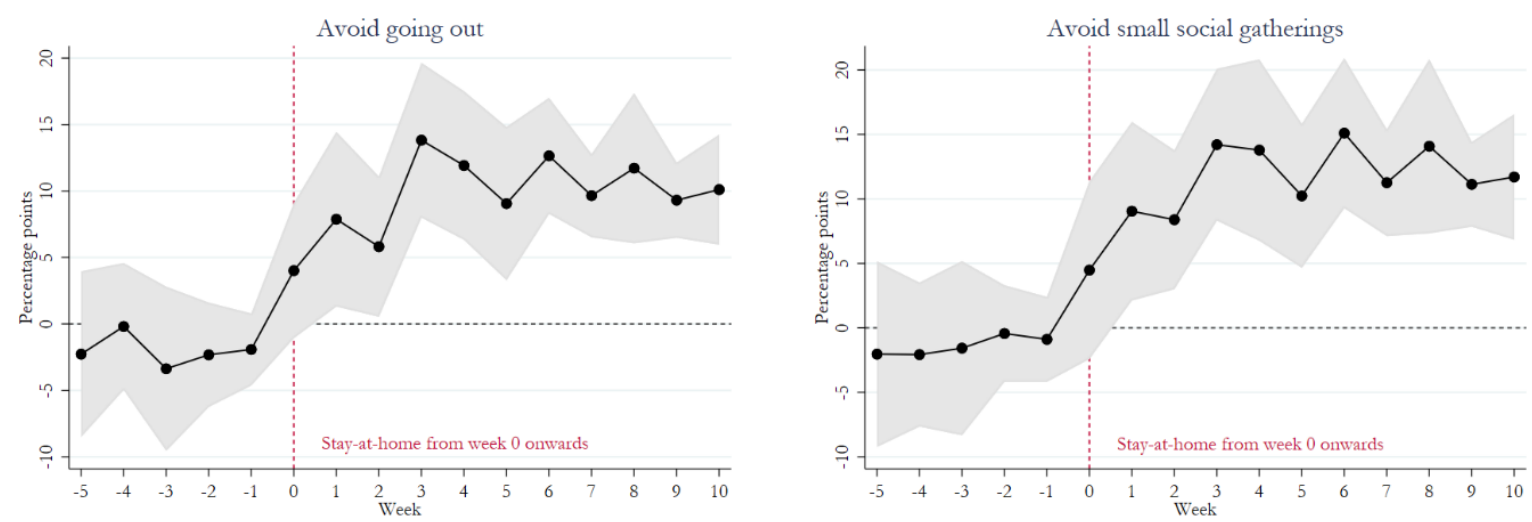

(b) Other restrictions
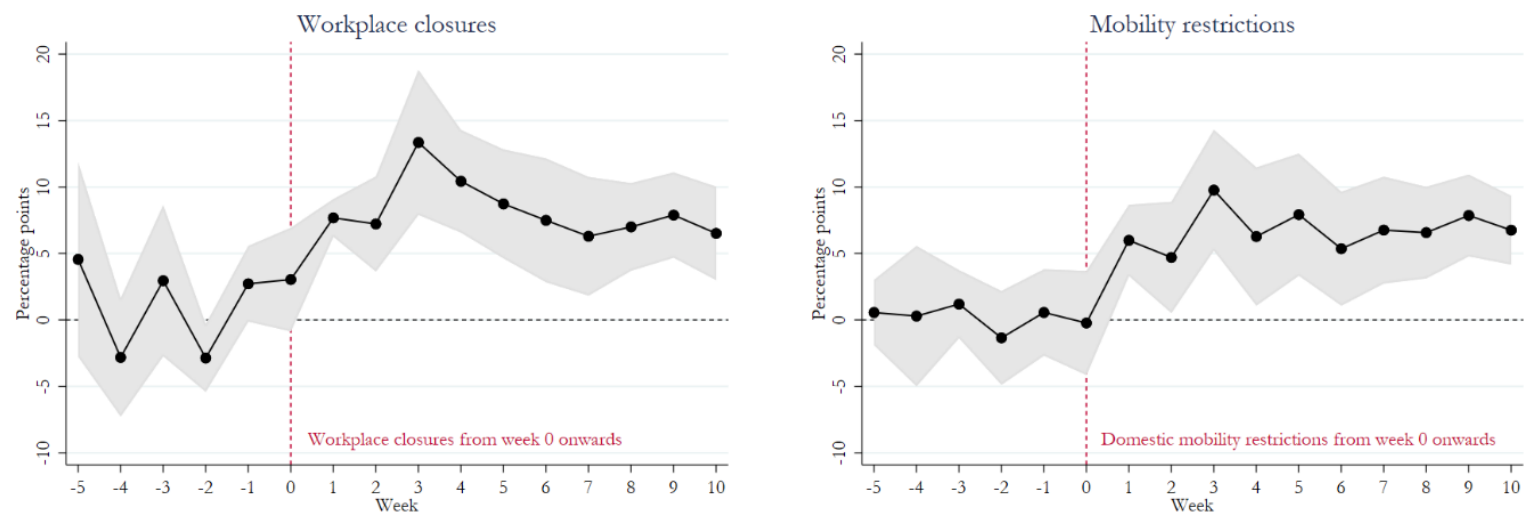

Note: The top panels show the impact of stay-at-home orders on the share of respondents avoiding going out of the home or avoiding small social gatherings (with fewer than two non-household members). The bottom panels examine the impact of workplace closures and domestic mobility restrictions on the physical distancing index. All regressions follow Equation (2), condition on country fixed effects, and control for age, gender, household composition, employment, respondent health status, and new confirmed COVID-19 deaths. The 95 percent confidence intervals are based on robust standard errors clustered on country.

Both policies are also associated with a large and persistent increase in physical distancing. The estimated impacts continue to be statistically significant, except in the very first week of implementation. Interestingly, the impact of all these different types of restrictions is quantitatively similar, indicating that much of the increase in physical distancing due to lockdowns is connected to workplace closures, and thus possibly caused by fewer work-related social interactions. 


\title{
How mask mandates impact mask wearing
}

Next, we examine the effect of mask mandates on self-reported mask wearing among the general public. We continue to use the specification in Equation (2), but now our dependent variable is an indicator variable that takes value one if individuals report wearing masks outside the home "Always" or "Frequently." In addition, we control for the overall stringency of government lockdowns, to capture any other policies that were introduced concurrently, and which could impact social distancing compliance.

\section{Figure 9. Mask mandates and mask wearing}

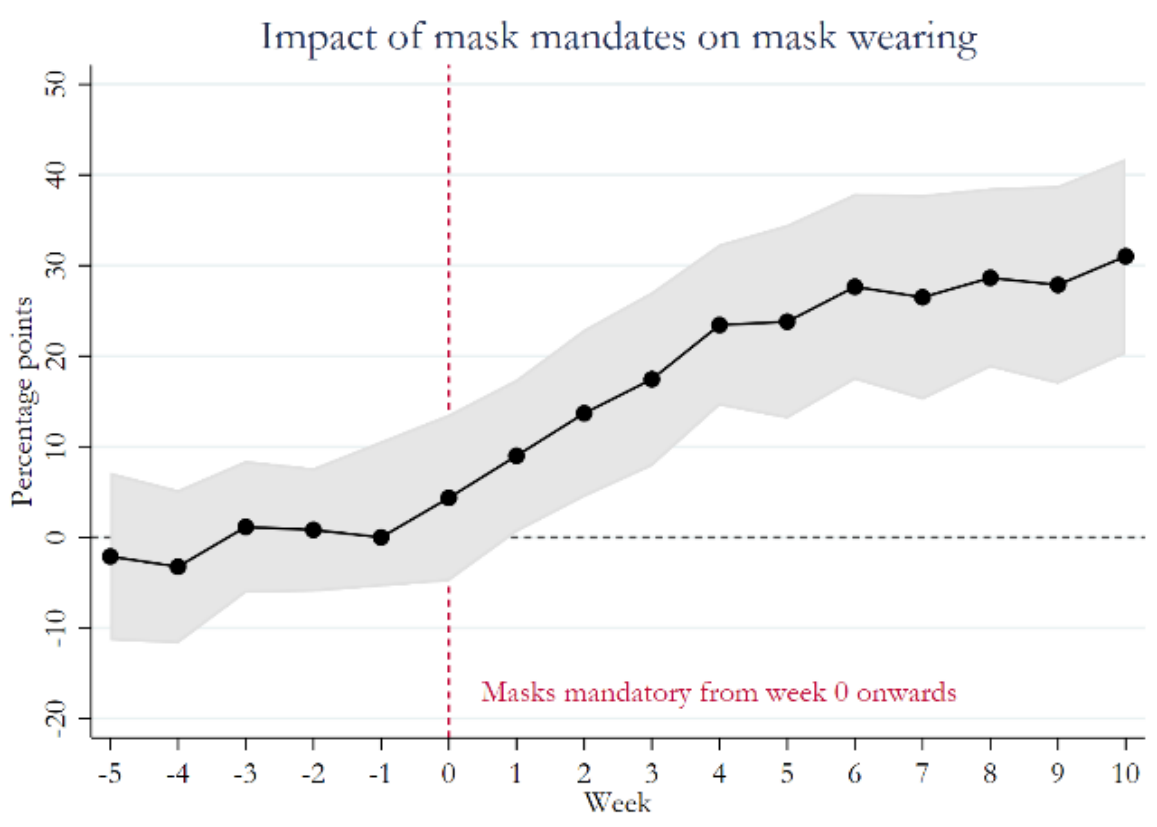

\begin{abstract}
Note: This figure shows the estimate impact of mask mandates on mask wearing (in percentage points), before and after mask mandates came into effect. The dashed red vertical line indicates week 0 , which is the week in which mask mandates were implemented. The specification follows Equation (2), conditions on country fixed effects, and controls for age, gender, household composition, employment, respondent health status, daily new COVID-19 deaths and overall lockdown stringency. The 95 percent confidence intervals are based on robust standard errors clustered on country.
\end{abstract}

Figure 9 shows that the implementation of mask mandates is associated with a clear increase in self-reported mask wearing that starts from the very first week of implementation. This result is consistent with other recent studies examining the impact of mask mandates in specific countries (e.g., Haischer et al., 2020; Karaivanov et al., 2020; Chernozhukov et al., 2020; Mitze et al., 2020). The impact builds over time, with self-reported mask usage on average increasing by about 30 percentage points above the pre-mandate baseline. The effect appears to peak about six weeks after mandates are implemented and remains stable thereafter. This suggests that the increase in mask wearing is persistent, at least while mask mandates remain in force. Figure 9 also displays the confidence intervals around these estimates, which show that the impact is statistically significant from early on. Importantly, we do not observe any significant anticipation effects, as the estimated coefficients before the implementation week are close to zero and not statistically significant. 
We also examine how the impact of mask mandates vary across groups. First, we focus on the effect of mask mandates in countries where mask wearing was less common before the pandemic. Specifically, we define countries as having a high baseline levels of mask wearing if more than half of the population reported frequent use of masks in February 2020. This group includes only countries in Asia. ${ }^{8}$ The top left panel in Figure 10 shows that the impact of mask mandates we estimate comes exclusively from countries with low baseline mask wearing. This is expected, since compliance in high baseline countries was high throughout our entire sample period.

\section{Figure 10. Heterogenous impacts of mask mandates}
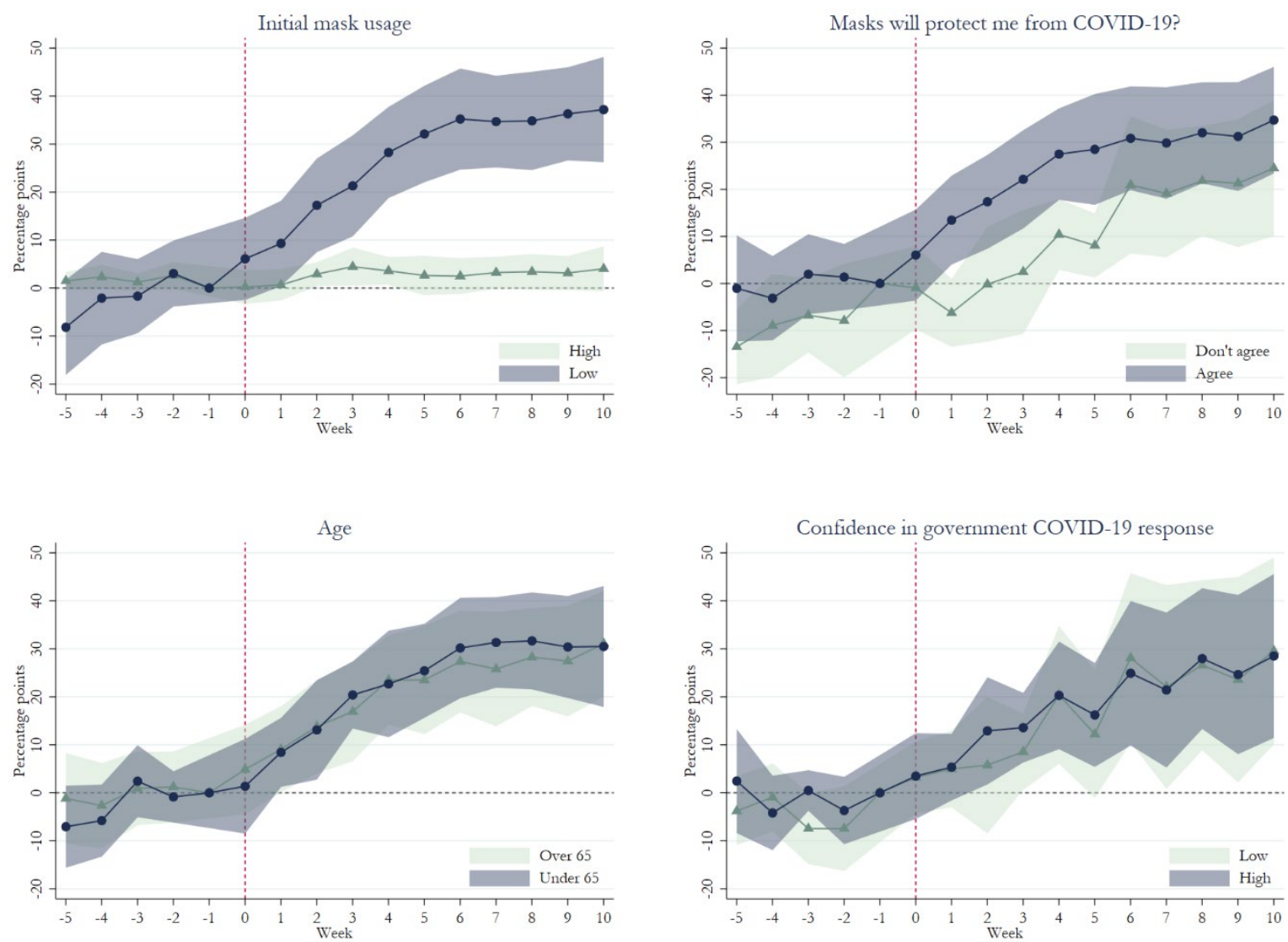

Note: These panels show the estimated impact of mask mandates, separating by subgroups. The specification is based on Equation (2), with the mask mandate policy variable interacted with group indicators. The top left panel separates between countries with high and low mask usage at the start of 2020 (defined as average mask usage above 50 percent in January 2020). The top right panel separates between individuals who agree or disagree that masks offer protection against COVID-19. The bottom panels examine responses by age (over or under 65 years old) and confidence in the government's response to COVID-19.

Next, we look at differences in the impact of mask mandates depending on personal beliefs regarding the effectiveness of masks. The results are shown in the top right panel in Figure 9. People who believe that masks will protect them (or others) from contracting COVID-19 respond

${ }^{8}$ China, Hong Kong SAR, Indonesia, Japan, Philippines, South Korea, Taiwan, province of China, Thailand, and Vietnam. 
more strongly to mask mandates than people with the opposite beliefs. Still, even among this latter group we see that mask mandates are associated with a significant increase in mask compliance.

Finally, in the bottom panels of Figure 10 we examine if there are differences in the impact of mask mandates by age or trust in the government response to COVID-19. We find that increases in mask wearing are similar across people with different levels of trust in the government. This suggests that differences in compliance due to varying trust in government can be overcome through mask mandates. One possibility is that mandates are associated with stronger enforcement, either through fines or social stigma, which create stronger incentives for people to comply. It is also possible that mask mandates raise awareness of the benefits of mask usage, which disproportionately benefits people with low trust in government since they may be less likely to be aware of that information.

\section{WHAT DRIVES REgIONAL DIFFERENCES IN COMPLIANCE?}

Finally, we bring together the analysis in the two previous sections to understand how much of the cross-country variation in compliance can be attributed to individual factors and government interventions. We start from the following specification:

$$
\text { Compliance }_{i, c, t}=\alpha+\lambda^{\prime} \text { Region }_{c}+\beta_{I}{ }^{\prime} \text { Individual }_{i, c, t}+\beta_{L}{ }^{\prime} \text { Policies }_{c, t}+\gamma^{\prime} Z_{i, c, t}+e_{i, c, t}
$$

where Compliance refers to the indicators of physical distancing and mask wearing we have been using, Region are indicator variables for geographical regions, and Individual and Policies capture different dimensions of individual characteristics and beliefs and government policies that explain compliance with social distancing, respectively.

Using the results from section IV, to account for variation in individual characteristics and beliefs we include controls for gender, age, employment status and sector, attitude towards COVID-19, and confidence in the government response. Government policies are again taken from the Oxford Covid-19 Government Response Tracker (Hale et al., 2020), as before. They include indicator variables for eight different types of policies related to containment and mitigation of COVID-19-including the implementation of stay-at-home orders, domestic and international mobility restrictions, limitations on social gatherings and use of public transport, and school and work closures-as well as mask mandates.

We start by estimating Equation (3) with only the regional indicators, and excluding all other controls, taking Asia as our comparator region. Because data is not available for some countries in the last months of 2020, we focus on regional differences in compliance between end-March and end-September, which allows us to maintain a balanced sample.

The baseline regional gaps are shown in the second column of Table 1. During this period, selfreported compliance with physical distancing and mask wearing was higher in the Americas (comprising the US, Canada, Mexico and Brazil) compared to Asia, likely reflecting the fact that 
infections in the first wave were contained earlier in Asia, but lower in Europe. We isolate Southern Europe (France, Italy and Spain) from Northern Europe since the compliance gaps among the latter countries are substantially higher, which is worth examining separately.

Table 1. Explaining regional differences in compliance (Asia = baseline)

\begin{tabular}{|c|c|c|c|c|c|c|}
\hline & \multirow{2}{*}{$\begin{array}{c}\text { Baseline gap } \\
\text { vs. Asia }\end{array}$} & \multicolumn{4}{|c|}{ Explained by controls } & \multirow{2}{*}{$\begin{array}{c}\text { Residual gap } \\
\text { vs. Asia }\end{array}$} \\
\hline & & Policies & Individual & Total & $\%$ & \\
\hline \multicolumn{7}{|l|}{ Physical distancing } \\
\hline Americas & 8.9 & 8.4 & -2.5 & 5.9 & $66 \%$ & 3.0 \\
\hline Southern Europe & -9.4 & -4.2 & -6.0 & -10.2 & $109 \%$ & 0.8 \\
\hline Northern Europe & -21.2 & -3.7 & -12.6 & -16.3 & $77 \%$ & -5.0 \\
\hline \multicolumn{7}{|l|}{ Mask wearing } \\
\hline Americas & 5.7 & 7.5 & -3.6 & 3.9 & $69 \%$ & 1.7 \\
\hline Southern Europe & 0.8 & 2.8 & -2.3 & 0.5 & $59 \%$ & 0.3 \\
\hline Northern Europe & -53.3 & -24.8 & -9.9 & -34.7 & $65 \%$ & -18.6 \\
\hline
\end{tabular}

Note: This table shows average regional differences in compliance, taking Asia as the baseline region, and shows how much of those regional gaps are explained by differences in policies and individual factors. Policies includes government policies related to containment, as well as government-imposed mask requirements, as recorded by the Oxford COVID-19 Government Response Tracker. Individual factors include age, gender, employment status and sector, attitude towards COVID-19 and confidence in the government response to COVID-19. Results are reported in percentage points, except for column 5 which is shown in percent.

Starting from this specification, we then ask how much of these regional differences in compliance can be explained by individual factors or government policies. To do so, we adopt the conditional decomposition proposed by Gelbach (2016). This decomposition quantifies how much of the change in some coefficients of interest-in our case, the region indicators-is due to including additional covariates, independently of the order in which these covariates are added. That is, starting from a baseline model excluding controls, and then estimating a "full" model including all relevant controls, the method proposed by Gelbach (2016) allows us to write

$$
\lambda^{\text {No Controls }}=\delta_{c}^{\text {Individual }}+\delta_{c}^{\text {Policies }}+\lambda^{\text {Full Controls }}
$$

where the $\delta$ represent the change in regional coefficients attributable to individual factors or government policies. The last term in Equation (4) represents the regional coefficients in a model with all controls, and can be interpreted as the residual average regional differences in compliance that are not explained by the controls. This residual variation may be due instead to other factors, including the level of community transmission of COVID-19, cultural and social norms, or the quality of enforcement and communication of public health policies.

The results of this decomposition are shown in the remaining columns of Table 1. Taken together, individual factors and government policies typically explain over two-thirds of the regional differences in compliance, although their relative importance depends on the region and type of social distancing behavior. For example, differences in government policies appear to be the key driver of lower rates of mask wearing in Northern European countries. This is 
consistent with our results in Section $V$ on the impact of mask mandates, and the fact that public health messaging in these countries did not emphasize mask wearing as strongly as in other countries. However, individual factors, and especially attitudes towards COVID-19 and trust in the government COVID-19 response, appear to play a larger role in explaining differences in selfreported physical distancing. This could reflect a role for social norms or public health communication in shaping individual beliefs about COVID-19 and driving compliance with social distancing.

\section{CONCLUSION}

In this paper, we use individual-level survey data for 29 advanced and emerging market economies to shed light on determinants of social distancing across individuals and countries since the start of the COVID-19 pandemic.

First, we find that adherence to physical distancing recommendations had been on the decline across most countries, with a notable increase in non-household contacts that is not fully captured by mobility data. This decline was accompanied by an uptick in mask wearing, particularly in countries where such behavior was not the norm prior to the pandemic. These trends likely reflect multiple factors, including easing of lockdowns, fatigue and complacency with COVID-19 restrictions, and people likely seeking to trade-off the costs of social distancing with an acceptable level of personal (and community) risk.

Second, the analysis provides evidence about gender and age compliance gaps for a broad range of advanced and emerging market economies. Self-reported compliance with preventive behaviors is consistently higher for women and older people across all measures, potentially reflecting risk attitudes, and appears unlikely to be driven by differences in labor market attachment or gender norms around domestic work and childcare responsibilities. Interestingly, we also find that occupational differences in compliance with mask wearing and physical distancing mirror gender and social norms within occupations. Higher compliance by women may contribute to gender differences in COVID-19 incidence and mortality and has broader implications for how to target public health messaging to contain COVID-19.

Third, people who trust their government's response to COVID-19 are also more likely to adopt recommended behaviors and are more willing to isolate if advised. Building and maintaining public trust in government's response is therefore crucial to contain the spread of the virus. This requires transparent and well-organized responses to COVID-19, consistent and clear communications, and well-coordinated actions on health and economic fronts. Unfortunately, confidence in the government's response appears to be declining in several countries, especially in those that had more severe COVID-19 outbreaks. This combination of eroding trust and lower compliance is likely to create challenges ahead of widespread vaccine rollouts.

In addition, we find that stay-at-home orders other mobility restrictions translate into reduced social interactions and behavioral responses to public health guidelines. Evidence suggests that lockdowns are particularly effective in curbing infections if they are introduced at an early stage 
of a country's epidemic but can be disproportionately costly for the most economically vulnerable segments of the population (IMF, 2020). Compliance differences across groups suggest an important role for "low cost" non-pharmaceutical interventions such as mask mandates in slowing the spread of infections. These interventions tend to have high social distancing multipliers-low implementation costs compared to their high potential benefits.

Finally, we show that individual factors-including demographics and attitudes towards COVID19-and government policies explain over two-thirds of the regional differences in compliance, This confirms the important role of public health policies in explaining differences in compliance across the globe, including in shaping individual beliefs about COVID-19. However, it also points to the relevance of other factors not discussed in this paper, including differences in social norms and the quality of public health communication and enforcement.

Our analysis suggests several interesting avenues for future research. First, it would be interesting to extend our analysis to alternative measures of compliance with recommended behaviors. In particular, self-reported compliance may be lower than actual compliance in many instances (e.g., Jakubowski, 2021), and also does not measure whether compliance is partial or incorrect (e.g., if a mask is worn incorrectly). Second, understanding how compliance relates to economic constraints faced by respondents would help shed light on policies needed to alleviate economic hardships. Finally, it would be interesting to understand how government policies impact individual attitudes towards COVID-19, and whether and how public health communication has managed to influence these attitudes over time. 


\section{REFERENCES}

Ajzenman, N., Cavalcanti, T. and Da Mata, D., (2020). More Than Words: Leaders' Speech and Risky Behavior during a Pandemic, London, Centre for Economic Policy Research. https://cepr.org/active/publications/discussion papers/dp.php?dpno $=14707$

Alberto, A., Stantcheva, S., and Teso, E., (2018). Intergenerational Mobility and Preferences for Redistribution, American Economic Review, 108 (2):521-54. https://www.aeaweb.org/articles?id=10.1257/aer.20162015

Allcott, H., Boxell, L., Conway, J. C., Gentzkow, M., Thaler, M., and Yang, D. Y., (2020). Polarization and Public Health: Partisan Differences in Social Distancing during the Coronavirus Pandemic, (Working Paper No. 26946; Working Paper Series). National Bureau of Economic Research. https://doi.org/10.3386/w26946

Barrios, J. M., and Hochberg, Y., (2020). Risk Perception Through the Lens of Politics in the Time of the COVID-19 Pandemic, (Working Paper No. 27008; Working Paper Series). National Bureau of Economic Research. https://doi.org/10.3386/w27008

Belot, M., Choi, S., Jamison, J. C., Papageorge, N. W., Tripodi, E., and Broek-Altenburg, E. V. D., (2020b). Unequal consequences of COVID-19 across age and income: Representative evidence from six countries, IZA Discussion Paper No. 13366.

Brodeur, A., Gray, D., Islam, A. and Bhuiyan, S. J., (2020). A Literature Review of the Economics of COVID-19, IZA Discussion Papers No. 13411. https://www.iza.org/publications/dp/13411/aliterature-review-of-the-economics-of-covid-19

Caselli, F. G., Grigoli, F., Sandri, D., and Spilimbergo, A., (2020). Mobility under the COVID-19 pandemic: Asymmetric effects across gender and age, CEPR Discussion Papers Nr. 15592.

Chernozhukov, V., Kasahara, H., and Schrimpf, P., (2020). Causal impact of masks, policies, behavior on early COVID-19 pandemic in the US. Journal of Econometrics. doi: 10.1016/j.jeconom.2020.09.003

Chiou, L., and Tucker, C., (2020). Social Distancing, Internet Access and Inequality, (Working Paper No. 26982; Working Paper Series). National Bureau of Economic Research. https://doi.org/10.3386/w26982

Coibion, O., Gorodnichenko, Y., and Weber, M., (2020). The Costs of the COVID-19 Crisis. Lockdowns, Macroeconomic Expectations and Consumer Spending, CESifo Working Paper No. 8292.

Croson, R., and Gneezy, U., (2009). Gender Differences in Preferences, Journal of Economic Literature, 47 (2):448-74. 
Dabla-Norris, E., F. Lima, and Khan H., (2021). The Social Distancing Gender Gap, IMF Working Paper (forthcoming).

Dong, E., Du, H. and Gardner, L., (2020). An interactive web-based dashboard to track COVID-19 in real time, Lancet Inf Dis. 20(5):533-534. https://doi.org/10.1016/S1473-3099(20)30120

Fan, Y., Orhun, A. Y., and Turjeman, D., (2020). Heterogeneous Actions, Beliefs, Constraints and Risk Tolerance During the COVID-19 Pandemic, (Working Paper No. 27211; Working Paper Series). National Bureau of Economic Research. https://doi.org/10.3386/w27211

Fetzer, T., Witte, M., Hensel, L., Jachimowicz, J., Haushofer, J., Ivchenko, A. and Yoeli, E., (2020, April 16). Perceptions of an Insufficient Government Response at the Onset of the COVID-19 Pandemic are Associated with Lower Mental Well-Being. https://doi.org/10.31234/osf.io/3kfmh

Galasso, V., Pons, V., Profeta, P., Becher, M., Brouard, S., and Foucault, M., (2020). Gender differences in COVID-19 attitudes and behavior: Panel evidence from eight countries, Proceedings of the National Academy of Sciences Oct 2020, 202012520; DOI: 10.1073/pnas.2012520117

Gelbach, J. B., (2016). When Do Covariates Matter? And Which Ones, and How Much? Journal of Labor Economics, 34 (2), pp. 509-543

Gozgor, G., (2020). Global Evidence on the Determinants of Public Trust in Governments during the COVID-19, CESifo Working Paper No. 8313

Haischer, M.H., Beilfuss, R., Hart, M. R., Opielinski, L., Wrucke, D., Zirgaitis, G., et al. (2020). Who is wearing a mask? Gender-, age-, and location-related differences during the COVID-19 pandemic. PLoS ONE 15(10): e0240785. https://doi.org/10.1371/journal.pone.0240785

Hale, T., Angrist, N., Cameron-Blake, E., Hallas, L., Kira, B., Majumdar, S., Petherick, A., Phillips, T., Tatlow, H. and Webster, S., (2020). Variation in government responses to COVID-19. BSG-WP2020/032

Han, Q., Zheng, B., Cristea, M., Agostini, M., Belanger, J., Gutzkow, B. and Leander, P. (2020, June 29). Trust in government and its associations with health behaviour and prosocial behaviour during the COVID-19 pandemic. https://doi.org/10.31234/osf.io/p5gns

IMF (2020). IMF World Economic Outlook, October 2020, Chapter 2: The Great Lockdown. Dissecting the Economic Effects.

Jakubowski, A., Egger, D., Nekesa, C., Lowe, L., Walker, M., and Miguel, E., (2021). Self-Reported Mask Wearing Greatly Exceeds Directly Observed Use: Urgent Need for Policy Intervention in Kenya. medRxiv 2021.01.27.21250487; doi: https://doi.org/10.1101/2021.01.27.21250487 
Jones, Sarah P., Imperial College London Big Data Analytical Unit and YouGov Plc. 2020, Imperial College London YouGov Covid Data Hub, v1.0, YouGov Plc, April 2020

Karaivanov, A., Lu, S., Shigeoka, H., Chen, C., and Pamplona, S., (2020). Face masks, public policies and slowing the spread of COVID-19: Evidence from Canada. medRxiv pre-print

Levin, A.T., Hanage, W.P., Owusu-Boaitey, N., et al. (2020). Assessing the age specificity of infection fatality rates for COVID-19: systematic review, meta-analysis, and public policy implications. Eur J Epidemiol 35, 1123-1138. https://doi.org/10.1007/s10654-020-00698-1

Li, S., Feng, B., Liao, W. and Pan, W., (2020). Internet Use, Risk Awareness, and Demographic Characteristics Associated With Engagement in Preventive Behaviors and Testing: CrossSectional Survey on COVID-19 in the United States, J Med Internet Res 2020;22(6):e19782 https://www.jmir.org/2020/6/e19782

Maloney, W., and Taskin, T., (2020). Determinants of Social Distancing and Economic Activity during COVID-19: A Global View. World Bank Policy Research Working Paper Nr. 9242.

Mitze, T., Kosfeld, R., Rode, J. and Wälde, K., (2020). Face masks considerably reduce COVID-19 cases in Germany, medRxiv pre-print.

Mohseni, M., and Lindstrom, M., (2007). Social capital, trust in the health-care system and selfrated health: The role of access to health care in a population-based study. Soc. Sci. Med.64, 1373-1383.

O'Driscoll, M., Ribeiro Dos Santos, G., Wang, L. et al. (2020). Age-specific mortality and immunity patterns of SARS-CoV-2. Nature. https://doi.org/10.1038/s41586-020-2918-0

Papageorge, N. W., Zahn, M. V., Belot, M., Broek-Altenburg E. V. D., Choi, S., Jamison, J. C., and Tripodi, E., (2020). Socio-Demographic Factors Associated with Self-Protecting Behavior during the Covid-19 Pandemic. NBER WP 27378 June 2020, doi 10.3386/w27378

Peckham, H., de Gruijter, N.M., Raine, C. et al. (2020). Male sex identified by global COVID-19 meta-analysis as a risk factor for death and ITU admission. Nat Commun 11, 6317. https://doi.org/10.1038/s41467-020-19741-6

Salmon, D. A., Dudley, M. Z., Glanz, J. M. and Omer, S. B., (2015). Vaccine Hesitancy Causes, Consequences, and a Call to Action. Am. J. Prev. Med.49, S391-S398.

Simonov, A., Sacher, S. K., Dubé, J.-P. H., and Biswas, S. (2020). The Persuasive Effect of Fox News: Non-Compliance with Social Distancing During the Covid-19 Pandemic, (Working Paper No. 27237) National Bureau of Economic Research. https://doi.org/10.3386/w27237

Yan, Y., Bayham, J., Richter, A. and Fenichel, E. (2020). Risk compensation and face mask mandates during the COVID-19 pandemic. Sci Rep 11, 3174 https://doi.org/10.1038/s41598$\underline{021-82574-w}$ 
IX. APPENDIX

\section{A.1. Other Tables}

Table A.1. Summary statistics

\begin{tabular}{|c|c|c|c|c|c|c|c|c|}
\hline & Mean & Std. Dev. & $10 \%$ & $25 \%$ & $50 \%$ & $75 \%$ & $90 \%$ & Obs \\
\hline \multicolumn{9}{|l|}{ Social Distancing } \\
\hline Mask wearing $(\mathrm{Y} / \mathrm{N})$ & 0.69 & 0.46 & 0.00 & 0.00 & 1.00 & 1.00 & 1.00 & 423,700 \\
\hline Physical distancing index $(\mathrm{Y} / \mathrm{N})$ & 0.38 & 0.48 & 0.00 & 0.00 & 0.00 & 1.00 & 1.00 & 423,700 \\
\hline Frequent handwashing $(\mathrm{Y} / \mathrm{N})$ & 0.91 & 0.28 & 1.00 & 1.00 & 1.00 & 1.00 & 1.00 & 423,700 \\
\hline Cover sneezes and coughs $(\mathrm{Y} / \mathrm{N})$ & 0.91 & 0.29 & 1.00 & 1.00 & 1.00 & 1.00 & 1.00 & 423,700 \\
\hline Clean high-contact surfaces $(\mathrm{Y} / \mathrm{N})$ & 0.60 & 0.49 & 0.00 & 0.00 & 1.00 & 1.00 & 1.00 & 423,700 \\
\hline Avoid people exposed $(\mathrm{Y} / \mathrm{N})$ & 0.82 & 0.39 & 0.00 & 1.00 & 1.00 & 1.00 & 1.00 & 423,700 \\
\hline Avoid small social gatherings $(\mathrm{Y} / \mathrm{N})$ & 0.61 & 0.49 & 0.00 & 0.00 & 1.00 & 1.00 & 1.00 & 423,700 \\
\hline Avoid medium-sized social gatherings $(\mathrm{Y} / \mathrm{N})$ & 0.71 & 0.45 & 0.00 & 0.00 & 1.00 & 1.00 & 1.00 & 423,700 \\
\hline Avoid large social gatherings $(\mathrm{Y} / \mathrm{N})$ & 0.81 & 0.39 & 0.00 & 1.00 & 1.00 & 1.00 & 1.00 & 423,700 \\
\hline \multicolumn{9}{|l|}{ Health Status } \\
\hline High-risk for COVID-19 (Y/N) & 0.00 & 0.00 & 0.00 & 0.00 & 0.00 & 0.00 & 0.00 & 423,700 \\
\hline Exhibiting COVID-19 symptoms $(\mathrm{Y} / \mathrm{N})$ & 0.10 & 0.30 & 0.00 & 0.00 & 0.00 & 0.00 & 0.00 & 423,700 \\
\hline Tested positive for COVID-19 (Y/N) & 0.01 & 0.10 & 0.00 & 0.00 & 0.00 & 0.00 & 0.00 & 423,700 \\
\hline Others tested positive for COVID-19 $(\mathrm{Y} / \mathrm{N})$ & 0.01 & 0.10 & 0.00 & 0.00 & 0.00 & 0.00 & 0.00 & 423,700 \\
\hline \multicolumn{9}{|l|}{ Demographics } \\
\hline Age & 43.96 & 16.32 & 23.00 & 30.00 & 42.00 & 57.00 & 67.00 & 423,700 \\
\hline Gender $($ Female $=1)$ & 0.50 & 0.50 & 0.00 & 0.00 & 1.00 & 1.00 & 1.00 & 423,700 \\
\hline Household size & 3.10 & 1.61 & 1.00 & 2.00 & 3.00 & 4.00 & 5.00 & 423,700 \\
\hline Household children & 0.86 & 1.19 & 0.00 & 0.00 & 0.00 & 1.00 & 2.00 & 423,700 \\
\hline \multicolumn{9}{|l|}{ Attitudes } \\
\hline Confidence in government response $(\mathrm{Y} / \mathrm{N})$ & 0.64 & 0.48 & 0.00 & 0.00 & 1.00 & 1.00 & 1.00 & 249,324 \\
\hline Confidence in health system response $(\mathrm{Y} / \mathrm{N})$ & 0.75 & 0.43 & 0.00 & 1.00 & 1.00 & 1.00 & 1.00 & 305,803 \\
\hline Afraid of contracting COVID-19 $(\mathrm{Y} / \mathrm{N})$ & 0.59 & 0.49 & 0.00 & 0.00 & 1.00 & 1.00 & 1.00 & 286,776 \\
\hline
\end{tabular}

Note: This table shows summary statistics for the full sample. 
Table A.2. Compliance by age and gender

\begin{tabular}{|c|c|c|c|c|c|c|}
\hline \multirow[b]{2}{*}{ Cohort } & \multicolumn{3}{|c|}{ Physical distancing } & \multicolumn{3}{|c|}{ Mask wearing } \\
\hline & Men & Women & Difference & Men & Women & Difference \\
\hline 18 to 24 & & $\begin{array}{c}4.99 * * * \\
(0.95)\end{array}$ & $\begin{array}{c}-4.99^{* * *} \\
(0.95)\end{array}$ & & $\begin{array}{c}3.68^{* * *} \\
(0.90)\end{array}$ & $\begin{array}{c}-3.68^{* * *} \\
(0.90)\end{array}$ \\
\hline 25 to 29 & $\begin{array}{c}4.70^{* * *} \\
(0.67)\end{array}$ & $\begin{array}{c}7.08^{* * *} \\
(1.01)\end{array}$ & $\begin{array}{c}-2.37^{* *} \\
(0.88)\end{array}$ & $\begin{array}{c}0.72 \\
(0.74)\end{array}$ & $\begin{array}{c}3.17^{* * *} \\
(1.09)\end{array}$ & $\begin{array}{c}-2.46^{* * *} \\
(0.78)\end{array}$ \\
\hline 30 to 34 & $\begin{array}{c}6.08^{* * *} \\
(1.12)\end{array}$ & $\begin{array}{c}9.84^{* * *} \\
(1.22)\end{array}$ & $\begin{array}{c}-3.76^{* * *} \\
(0.95)\end{array}$ & $\begin{array}{c}0.98 \\
(0.81)\end{array}$ & $\begin{array}{c}2.99^{* *} \\
(1.13)\end{array}$ & $\begin{array}{c}-2.00^{* *} \\
(0.85)\end{array}$ \\
\hline 35 to 39 & $\begin{array}{c}6.36^{* * *} \\
(1.17)\end{array}$ & $\begin{array}{c}11.78^{* * *} \\
(1.29)\end{array}$ & $\begin{array}{c}-5.42^{* * *} \\
(0.74)\end{array}$ & $\begin{array}{c}0.35 \\
(1.14)\end{array}$ & $\begin{array}{c}3.21^{* *} \\
(1.21)\end{array}$ & $\begin{array}{c}-2.86^{* * *} \\
(0.63)\end{array}$ \\
\hline 40 to 44 & $\begin{array}{c}5.64^{* * *} \\
(1.04)\end{array}$ & $\begin{array}{c}12.26^{* * *} \\
(1.16)\end{array}$ & $\begin{array}{c}-6.62^{* * *} \\
(0.88)\end{array}$ & $\begin{array}{l}-0.12 \\
(1.00)\end{array}$ & $\begin{array}{l}2.66^{*} \\
(1.38)\end{array}$ & $\begin{array}{c}-2.77^{* * *} \\
(0.64)\end{array}$ \\
\hline 45 to 49 & $\begin{array}{c}7.49^{* * *} \\
(1.12)\end{array}$ & $\begin{array}{c}14.45^{* * *} \\
(1.25)\end{array}$ & $\begin{array}{c}-6.96^{* * *} \\
(0.73)\end{array}$ & $\begin{array}{l}-0.76 \\
(1.28)\end{array}$ & $\begin{array}{c}2.96^{* *} \\
(1.38)\end{array}$ & $\begin{array}{c}-3.73^{* * *} \\
(0.51)\end{array}$ \\
\hline 50 to 54 & $\begin{array}{c}8.28^{* * *} \\
(1.12)\end{array}$ & $\begin{array}{c}16.18^{* * *} \\
(1.26)\end{array}$ & $\begin{array}{c}-7.90^{* * *} \\
(0.84)\end{array}$ & $\begin{array}{l}-0.24 \\
(1.42)\end{array}$ & $\begin{array}{l}3.09^{*} \\
(1.78)\end{array}$ & $\begin{array}{c}-3.32^{* * *} \\
(0.97)\end{array}$ \\
\hline 55 to 59 & $\begin{array}{c}9.46^{* * *} \\
(1.11)\end{array}$ & $\begin{array}{c}18.24^{* * *} \\
(1.25)\end{array}$ & $\begin{array}{c}-8.78^{* * *} \\
(0.74)\end{array}$ & $\begin{array}{l}-0.17 \\
(1.52)\end{array}$ & $\begin{array}{l}4.08^{* *} \\
(1.64)\end{array}$ & $\begin{array}{c}-4.25^{* * *} \\
(0.65)\end{array}$ \\
\hline 60 to 64 & $\begin{array}{c}8.95 * * * \\
(1.27)\end{array}$ & $\begin{array}{c}19.96^{* * *} \\
(1.46)\end{array}$ & $\begin{array}{c}-11.01^{* * * *} \\
(0.87)\end{array}$ & $\begin{array}{l}-0.28 \\
(1.79)\end{array}$ & $\begin{array}{l}4.44^{* *} \\
(1.69)\end{array}$ & $\begin{array}{c}-4.72^{* * *} \\
(0.82)\end{array}$ \\
\hline 65 to 69 & $\begin{array}{c}9.95 * * * \\
(1.53)\end{array}$ & $\begin{array}{c}21.41^{* * *} \\
(1.52)\end{array}$ & $\begin{array}{c}-11.47^{* * *} \\
(1.05)\end{array}$ & $\begin{array}{c}0.79 \\
(1.64)\end{array}$ & $\begin{array}{l}4.76^{* *} \\
(1.99)\end{array}$ & $\begin{array}{c}-3.97^{* * *} \\
(0.80)\end{array}$ \\
\hline 70 to 74 & $\begin{array}{c}11.08^{* * *} \\
(1.55)\end{array}$ & $\begin{array}{c}22.81^{* * *} \\
(1.79)\end{array}$ & $\begin{array}{c}-11.73^{* * *} \\
(1.38)\end{array}$ & $\begin{array}{c}1.16 \\
(2.08)\end{array}$ & $\begin{array}{c}5.48^{* *} \\
(2.37)\end{array}$ & $\begin{array}{c}-4.32^{* * *} \\
(0.76)\end{array}$ \\
\hline 75 and over & $\begin{array}{c}10.64^{* * *} \\
(1.50)\end{array}$ & $\begin{array}{c}23.19^{* * *} \\
(1.75)\end{array}$ & $\begin{array}{c}-12.55^{* * *} \\
(1.06)\end{array}$ & $\begin{array}{c}1.70 \\
(2.23)\end{array}$ & $\begin{array}{c}5.63^{* *} \\
(2.59)\end{array}$ & $\begin{array}{c}-3.92^{* * *} \\
(1.37)\end{array}$ \\
\hline Survey FE & Yes & Yes & Yes & Yes & Yes & Yes \\
\hline Controls & Yes & Yes & Yes & Yes & Yes & Yes \\
\hline Obs & 422,764 & 422,764 & 422,764 & 422,764 & 422,764 & 422,764 \\
\hline
\end{tabular}

Note: This table shows the average difference in compliance by age and gender, relative to the cohort of $18-24$ year old males, as depicted in Figure 3. The coefficients are estimated using the specification in Equation (1), in percentage points. Columns 1 and 2 show the estimated coefficients for men and women from the same regression using the physical distancing index as the dependent variable, while columns 4-5 show similar analysis for mask wearing. Both regressions include survey fixed effects, and control for household size, number of children, employment status and occupation, and respondent health status. Columns 3 and 6 test the difference between coefficients for men and women, by age cohort. Standard errors (in brackets) are clustered by country. ${ }^{*} 0.10$ ** $0.05 * * * 0.01$ 
Table A.3. Compliance by employment sector

\begin{tabular}{lcc}
\hline \hline & Physical distancing & Mask wearing \\
\hline Construction & 1.12 & $-2.13^{* * *}$ \\
Home Deliveries & $(0.85)$ & $(0.58)$ \\
& 1.79 & -1.80 \\
Food Services & $(1.52)$ & $(1.28)$ \\
& $2.41^{* *}$ & 0.48 \\
Healthcare & $(0.95)$ & $(0.80)$ \\
& -0.11 & 1.30 \\
Logistics & $(0.75)$ & $(0.80)$ \\
& 0.50 & $-2.96^{* * *}$ \\
Security & $(0.92)$ & $(0.57)$ \\
& $-3.14^{* *}$ & $-3.10^{* *}$ \\
Public Transport & $(1.31)$ & $(1.43)$ \\
& -0.66 & 0.53 \\
Education & $(1.10)$ & $(1.25)$ \\
Social Services & $-1.57^{*}$ & -1.44 \\
& $(0.86)$ & $(0.90)$ \\
Hospitality & -0.36 & 0.05 \\
& $(0.87)$ & $(0.92)$ \\
Work From Home & 0.71 & 0.80 \\
& $(0.92)$ & $(1.15)$ \\
Survey FE & $6.34^{* * *}$ & $1.17^{* *}$ \\
Controls & $(0.75)$ & $(0.56)$ \\
Obs & Yes & Yes \\
\hline \hline
\end{tabular}

Note: This table shows average compliance differences by employment sector, in percentage points, as depicted in Figure 4. The baseline group is manufacturing workers that are not able telework, and the sample is restricted to full and part-time workers. Both regressions include survey fixed effects, and control for household size, number of children, and respondent health status. Standard errors (shown in brackets) are clustered by country. ${ }^{*} 0.10{ }^{* *} 0.05{ }^{* \star *} 0.01$ 


\section{A.2. Other Figures}

Figure A.1. Data Availability by Country and Week

\begin{tabular}{|c|c|c|c|c|c|c|c|c|c|c|c|c|c|c|c|c|c|c|c|c|c|c|c|c|c|c|c|c|c|c|c|c|}
\hline Week starting & $3 / 30$ & $4 / 6$ & $4 / 13$ & $4 / 20$ & $4 / 27$ & $5 / 4$ & $5 / 11$ & $5 / 18$ & $5 / 25$ & $6 / 1$ & $6 / 8$ & $6 / 15$ & $6 / 22$ & $6 / 29$ & $7 / 6$ & $7 / 20$ & $7 / 27$ & $8 / 3$ & $8 / 10$ & $8 / 17$ & $8 / 24$ & $8 / 31$ & $9 / 7$ & 9/14 & $9 / 21$ & $9 / 281$ & $10 / 12$ & $10 / 26$ & $11 / 9$ & & $12 / 21$ & Total \\
\hline United Arab Emirates & & 1 & & 1 & & & 1 & & 1 & 1 & & & 1 & & 1 & 1 & & 1 & & 1 & & 1 & & 1 & & & & & & & & 12 \\
\hline Australia & 1 & & 1 & & 1 & 1 & 1 & & & 1 & & & 1 & & 1 & 1 & & 1 & & 1 & & 1 & & 1 & & 1 & 1 & 1 & 1 & 1 & 1 & \\
\hline Brazil & 1 & & & 1 & & & 1 & & & 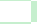 & 1 & & 1 & & 1 & 1 & & 1 & & 1 & & 1 & & 1 & & & & & & & & \\
\hline Canada & 1 & & & 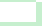 & 1 & . & 1 & & & 1 & & & 1 & & 1 & 1 & & 1 & & 1 & & 1 & & 1 & & 1 & 1 & 1 & 1 & 1 & & 17 \\
\hline China & 1 & 1 & 1 & 1 & 1 & 1 & 1 & & 1 & 1 & & & 1 & & 1 & 1 & & 1 & & 1 & & 1 & & 1 & & & & & & & & \\
\hline Germany & 1 & 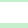 & 1 & 1 & 1 & 1 & 1 & & 1 & 1 & & & 1 & & 1 & 1 & & 1 & & 1 & & 1 & & 1 & & 1 & 1 & 1 & 1 & 1 & & 21 \\
\hline Denmark & 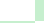 & 1 & & 1 & & 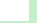 & 1 & & 1 & 1 & & & 1 & & 1 & 1 & & 1 & & 1 & & 1 & & 1 & & 1 & 1 & 1 & 1 & 1 & 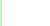 & 18 \\
\hline Spain & 1 & & 1 & 1 & 1 & 1 & 1 & & 1 & 1 & & & 1 & & 1 & 1 & & 1 & & 1 & & 1 & & 1 & & 1 & 1 & 1 & 1 & 1 & & \\
\hline Finland & 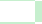 & 1 & & 1 & & 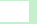 & 1 & & 1 & 1 & & & 1 & & 1 & 1 & & 1 & & 1 & & 1 & & 1 & & 1 & 1 & 1 & 1 & 1 & 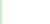 & 18 \\
\hline France & 1 & & 1 & 1 & 1 & 1 & 1 & & 1 & 1 & & & 1 & & 1 & 1 & & 1 & & 1 & & 1 & & 1 & & 1 & 1 & 1 & 1 & 1 & 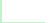 & 21 \\
\hline United Kingdom & 1 & & 1 & & 1 & 1 & 1 & & 1 & 1 & & 1 & 1 & & 1 & 1 & 1 & 1 & & 1 & & 1 & 1 & & 1 & 1 & 1 & 1 & 1 & 1 & 1 & 27 \\
\hline Hong Kong SAR & & 1 & & 1 & & & 1 & & 1 & 1 & & & 1 & & 1 & 1 & & 1 & & 1 & & 1 & & 1 & & & & & & & & \\
\hline Indonesia & & 1 & & 1 & & & 1 & & 1 & 1 & & & 1 & & 1 & 1 & & 1 & & 1 & & 1 & & 1 & & & & & & & & 12 \\
\hline India & 1 & & 1 & 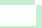 & 1 & 1 & 1 & & 1 & 1 & & 1 & & & 1 & 1 & 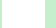 & 1 & & 1 & & 1 & & 1 & & & & & & & & 14 \\
\hline Italy & 1 & & 1 & 1 & 1 & 1 & 1 & & 1 & 1 & & & 1 & & 1 & 1 & & 1 & & 1 & & 1 & & 1 & & 1 & 1 & 1 & 1 & 1 & & \\
\hline Japan & 1 & & & 1 & & & 1 & & & & 1 & & 1 & & 1 & 1 & & 1 & & 1 & & 1 & & 1 & & 1 & 1 & 1 & 1 & 1 & 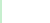 & 17 \\
\hline South Korea & 1 & & & 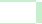 & 1 & & 1 & & & & 1 & & 1 & & 1 & 1 & 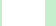 & 1 & & 1 & & 1 & & 1 & & 1 & 1 & 1 & 1 & 1 & & 17 \\
\hline Mexico & 1 & & & 1 & & & 1 & & 1 & 1 & & & 1 & & 1 & 1 & & 1 & & 1 & & 1 & & 1 & & & & & & & & 12 \\
\hline Malaysia & & 1 & & 1 & & & 1 & & 1 & 1 & & & 1 & & 1 & 1 & & 1 & & 1 & & 1 & & 1 & & & & & & & & \\
\hline Netherlands & & 1 & & 1 & & & 1 & & & & 1 & & 1 & & 1 & 1 & & 1 & & 1 & & 1 & & 1 & & 1 & 1 & 1 & 1 & 1 & & \\
\hline Norway & & 1 & & 1 & & & 1 & & 1 & 1 & & & 1 & & 1 & 1 & & 1 & & 1 & & 1 & & 1 & & 1 & 1 & 1 & 1 & 1 & & 18 \\
\hline Philippines & & 1 & & 1 & & & 1 & & 1 & 1 & & & 1 & & 1 & 1 & & 1 & & 1 & & 1 & & 1 & & & & & & & & \\
\hline Saudi Arabia & & 1 & & 1 & & & 1 & & 1 & 1 & & & 1 & & 1 & 1 & & 1 & & 1 & & 1 & & 1 & & & & & & & & 12 \\
\hline Singapore & 1 & & & 1 & & & 1 & & 1 & 1 & & & 1 & & 1 & 1 & 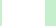 & 1 & & 1 & & 1 & & 1 & & 1 & 1 & 1 & 1 & 1 & 1 & 18 \\
\hline Sweden & 1 & & 1 & 1 & 1 & 1 & 1 & & 1 & 1 & & & 1 & & 1 & 1 & & 1 & & 1 & & 1 & & 1 & & 1 & 1 & 1 & 1 & 1 & & 21 \\
\hline Thailand & & 1 & & 1 & & & 1 & & 1 & 1 & & & 1 & & 1 & 1 & & 1 & & 1 & & 1 & & 1 & & & & & & & & 12 \\
\hline Taiwan, Province & & 1 & & 1 & & & 1 & & 1 & 1 & & & 1 & & 1 & 1 & & 1 & & 1 & & 1 & & 1 & & & & & & & & 12 \\
\hline United States & 1 & & 1 & & 1 & 1 & 1 & & 1 & 1 & & & 1 & & 1 & 1 & & 1 & & 1 & & 1 & & 1 & & & & & & & & 14 \\
\hline Vietnam & & 1 & & 1 & & & 1 & & 1 & 1 & & & 1 & & 1 & 1 & 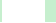 & 1 & & 1 & & 1 & & 1 & & & & & & & & 12 \\
\hline Total & 16 & 14 & 10 & 23 & 12 & 10 & 29 & 1 & 23 & 25 & 4 & 2 & 28 & 1 & 29 & 29 & 1 & 29 & 1 & 29 & 1 & 29 & 1 & 28 & 1 & 15 & 15 & 15 & 15 & 15 & 3 & \\
\hline
\end{tabular}

Note: This figure shows, for each country, in each week surveys were conducted. 
Figure A.2. Declining social distancing (all countries)
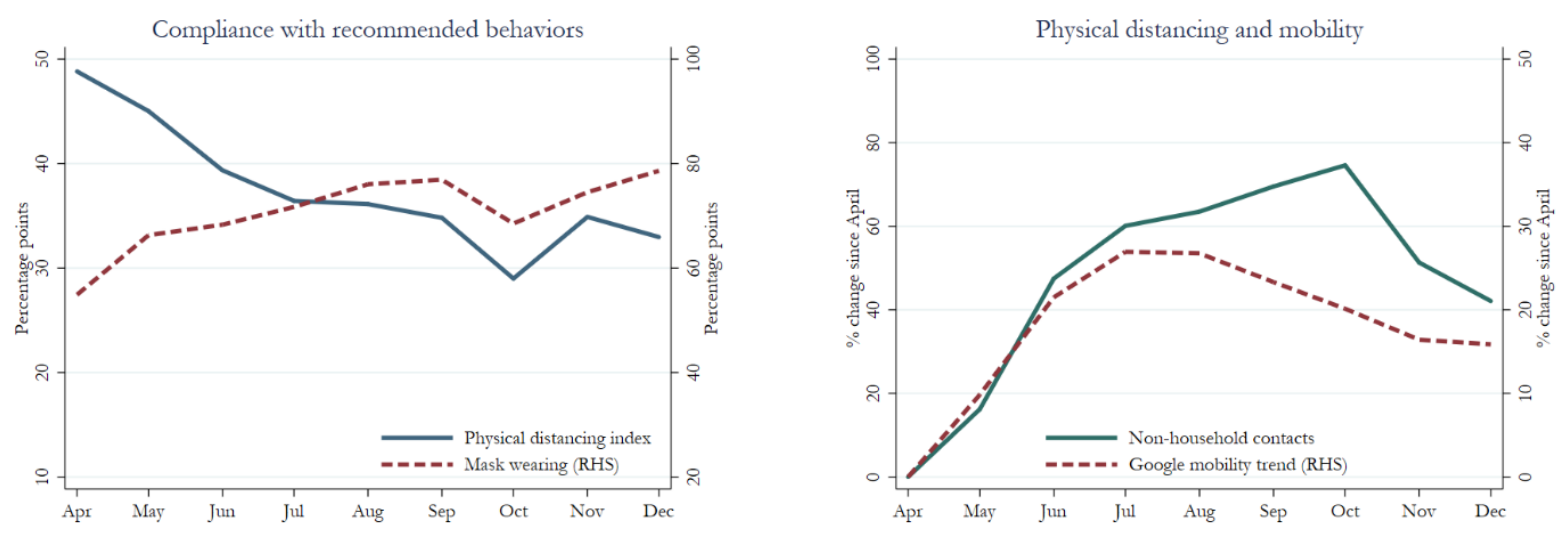

Note: The left panel shows the share of respondents that comply with mask wearing and recommended physical distancing behaviors-frequent handwashing, covering coughs and sneezes, cleaning frequently touched surfaces, avoiding people exposed to COVID-19 and avoiding small social gatherings. The right panel shows the average percent change in contacts with people outside the respondents' household and the Google mobility trends indicator, relative to a country-specific April baseline.

\section{Figure A.3. Social distancing by age and gender, full-time workers}
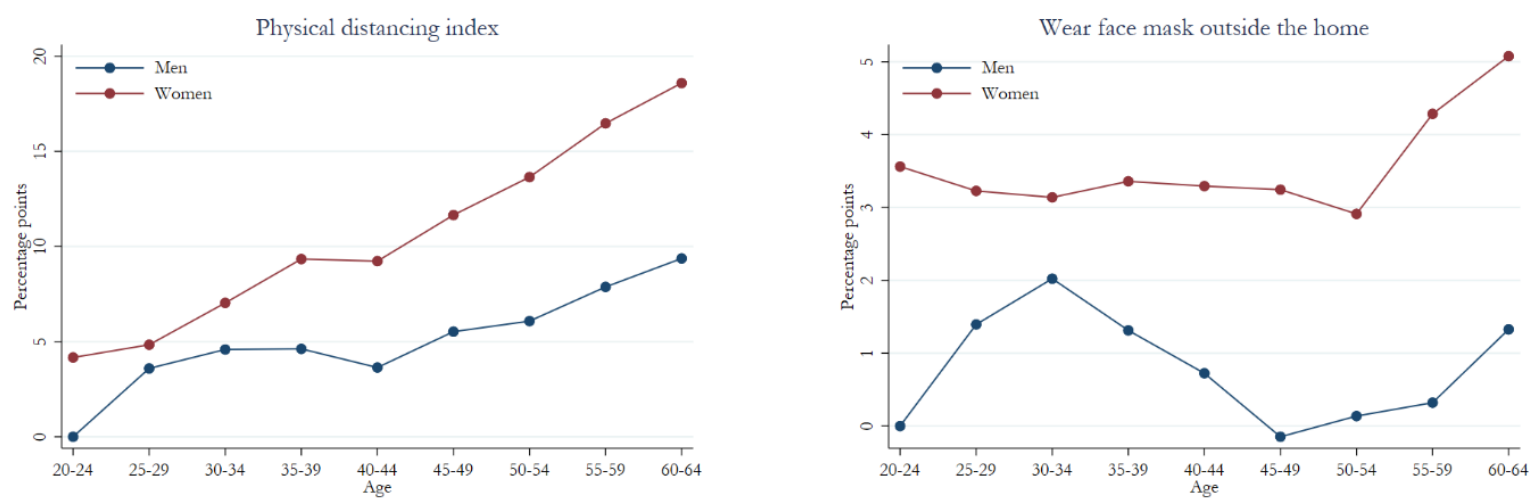

Note: This reproduces Figure 3, but restricting the sample to respondents in full-time work. Each panel shows the average change in compliance relative to the cohort of $18-24$ year old males, in percentage points, estimated using Equation (1). 
Figure A.4. Social distancing by age and gender, other behaviors
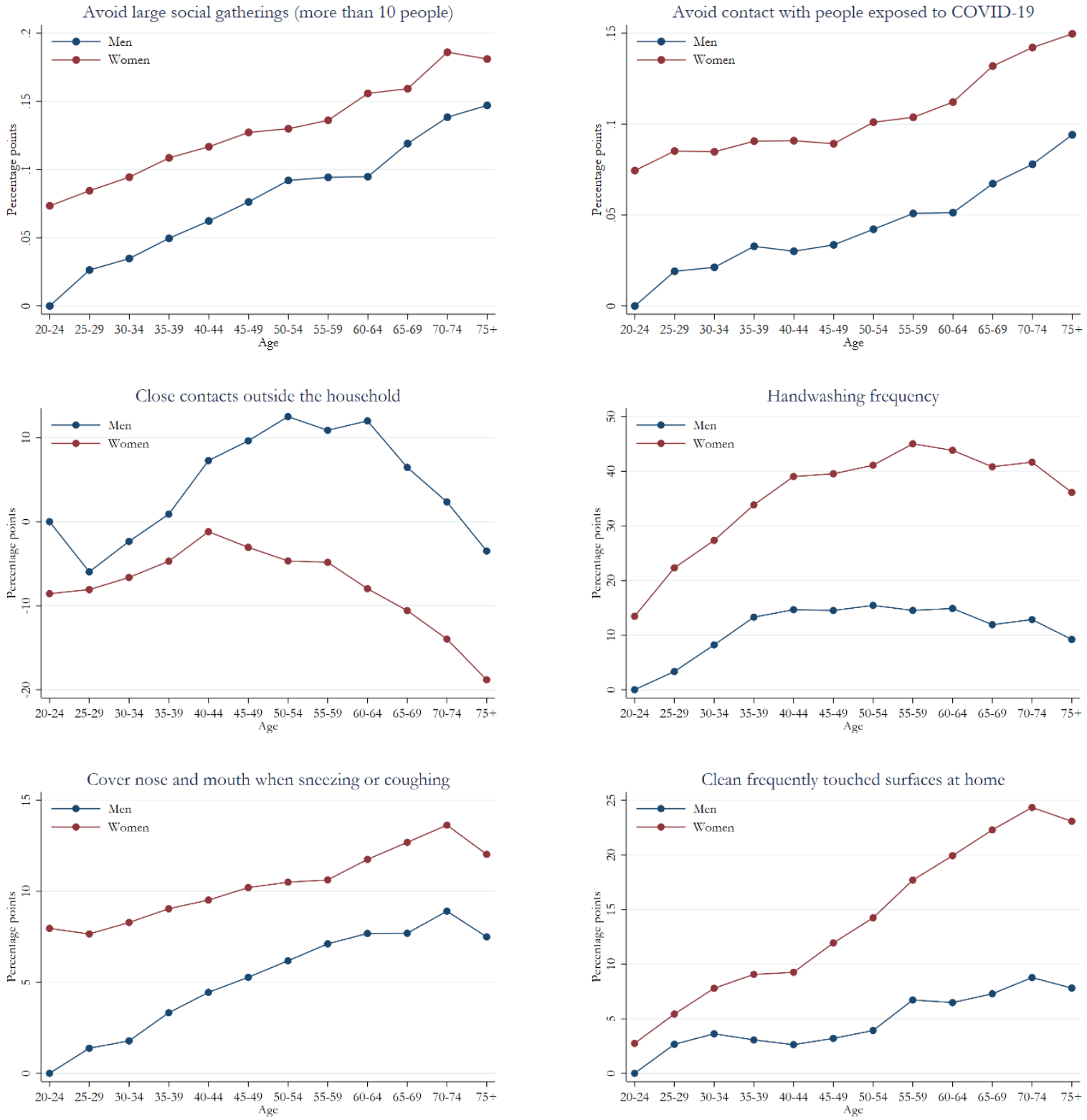

Note: The panels show the average difference in compliance by age and gender, relative to the cohort of 18 to 24 year old males. The coefficients are estimated using Equation (1), in percentage points, as described in Figure 3. 
Figure A.5. Social distancing by fear of contracting COVID-19
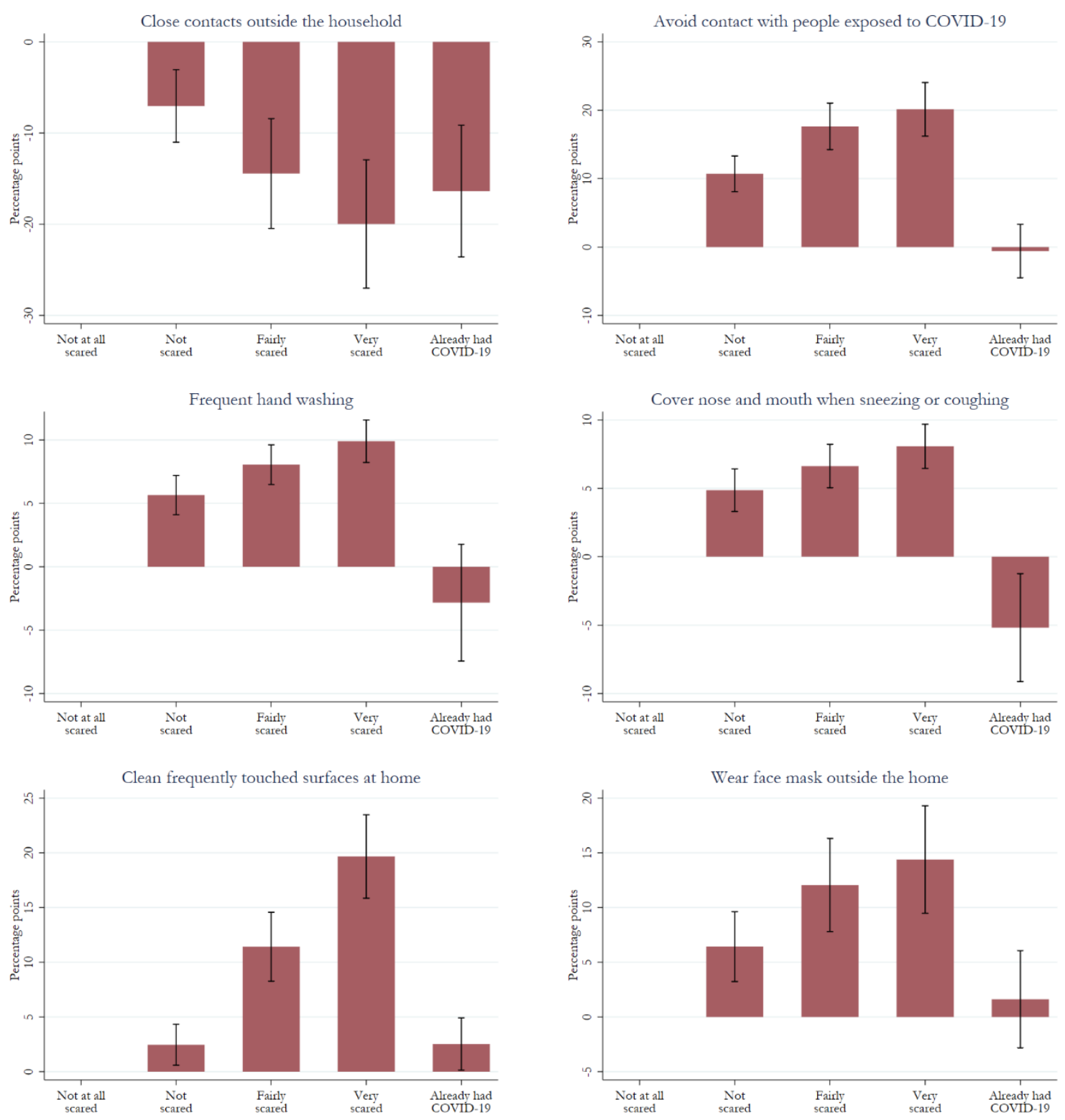

Note: Panels show the average increase or decline in compliance relative to respondents that report feeling not at all scared of contracting COVID-19, in percentage points. The 95 percent confidence intervals are based on robust standard errors clustered on country. All panels are based on the specification in Equation (1), conditional on survey fixed effects, and include controls for age, gender, household composition, employment, and health status. 
Figure A.6. Social distancing by trust in the government's response to COVID-19
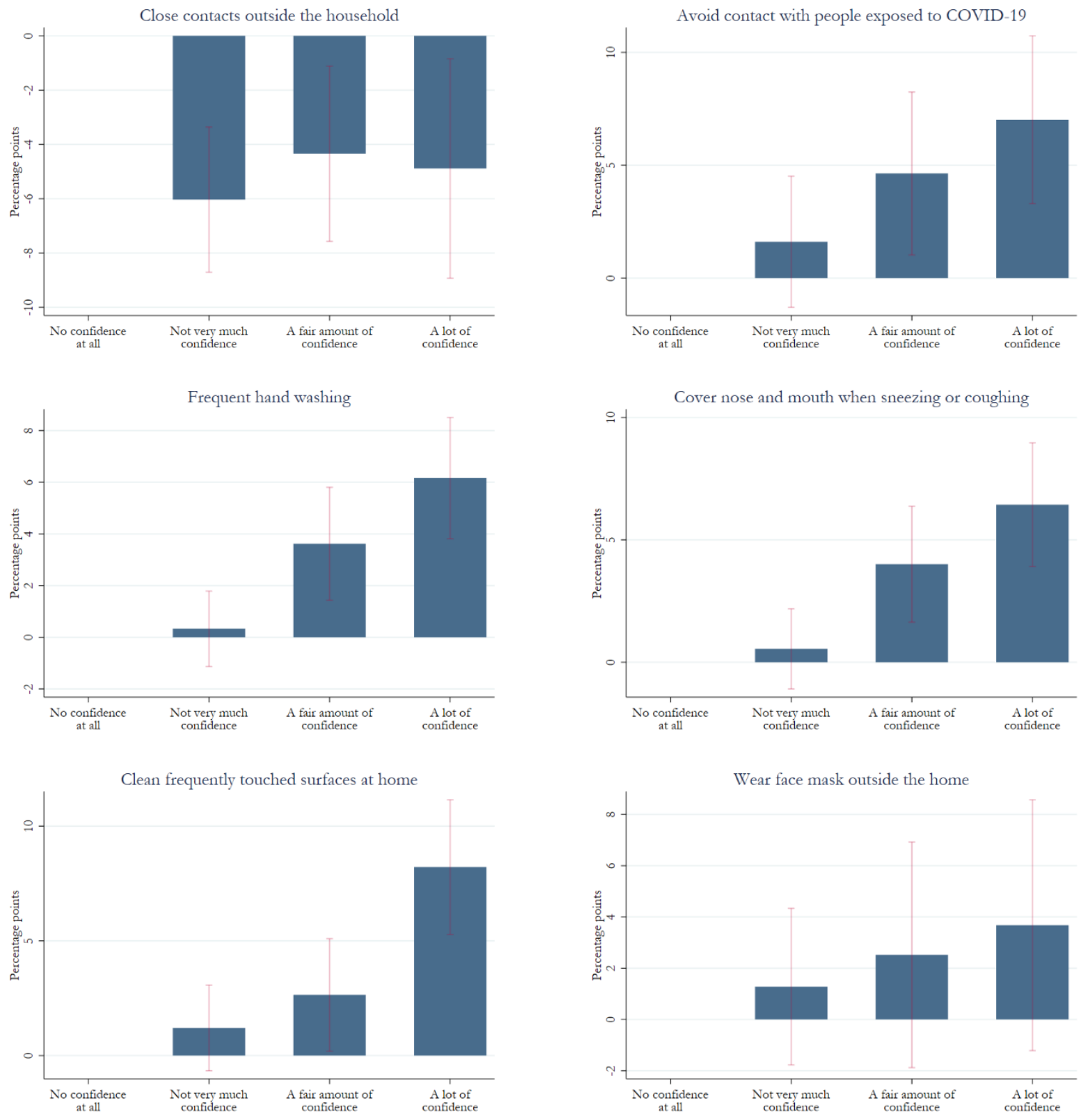

Note: Panels show the average increase or decline in compliance relative to respondents with no confidence at all in their government's response to COVID-19, in percentage points. The 95 percent confidence intervals are based on robust standard errors clustered on country. All panels are based on the specification in Equation (1), conditional on survey fixed effects, and include controls for age, gender, household composition, employment, and health status. 